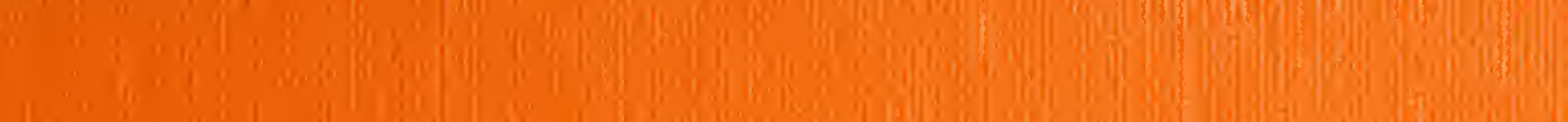
$x+3 x^{2}$

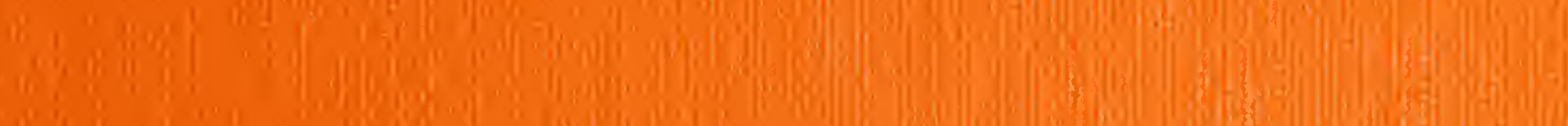
(n)

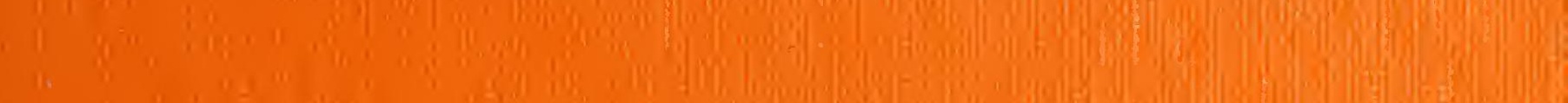
"

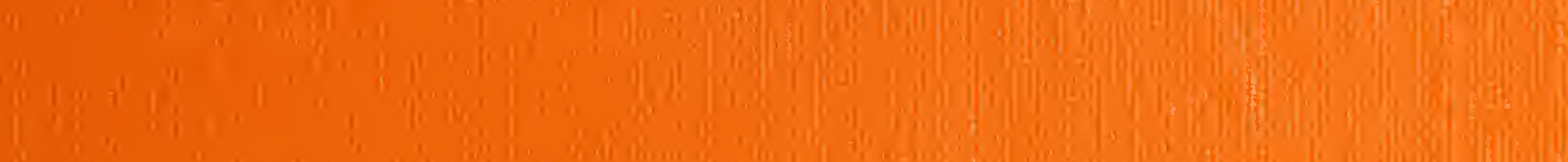
a. "

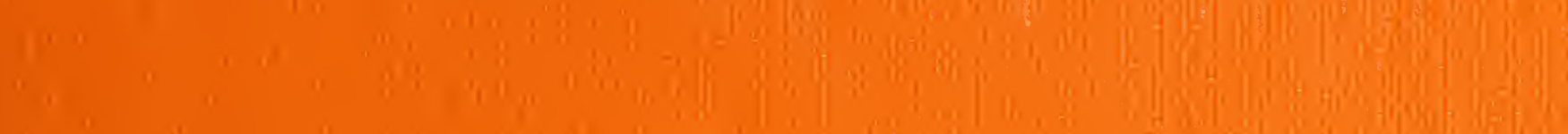

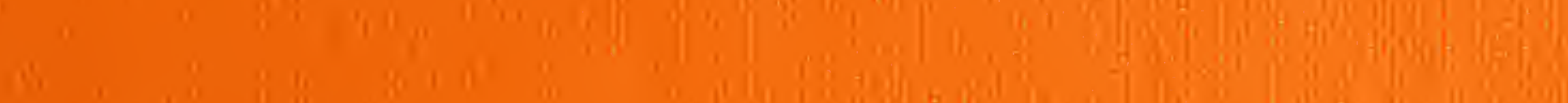

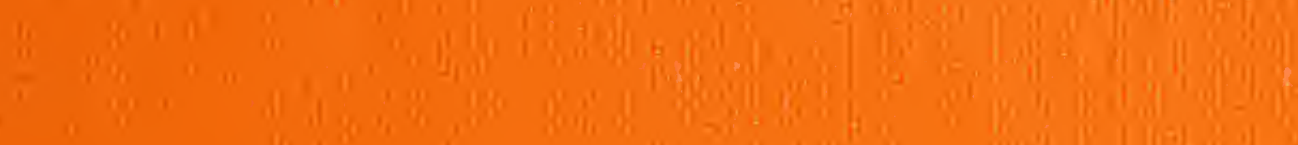
,

8

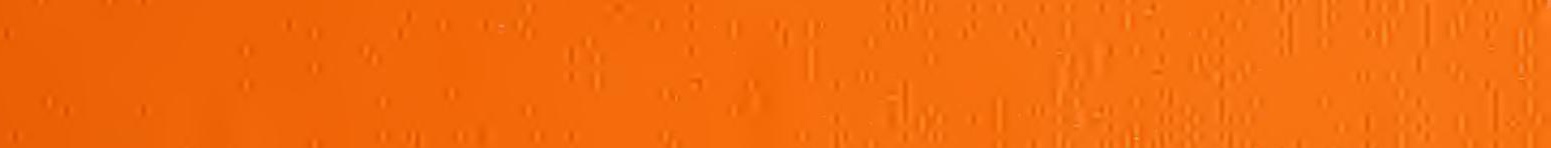

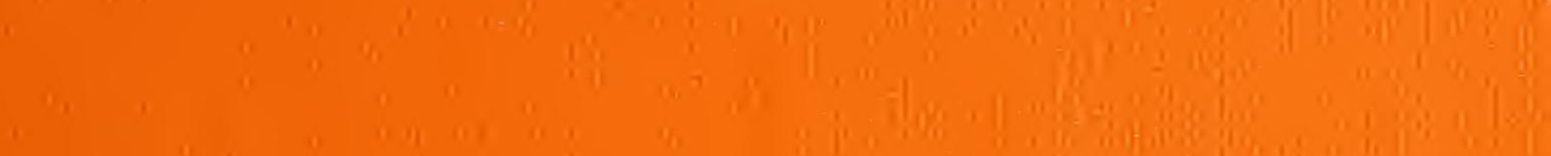

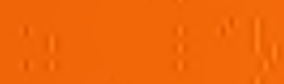
If 111 $x^{2}$



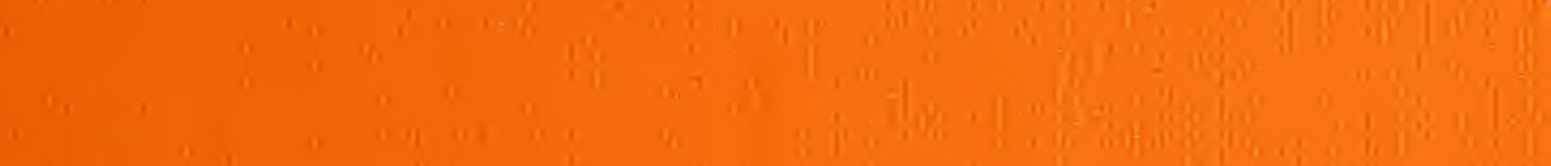
I.

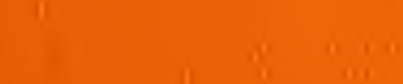
and

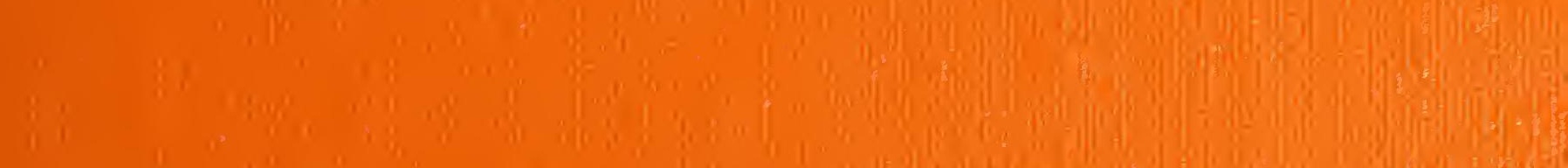

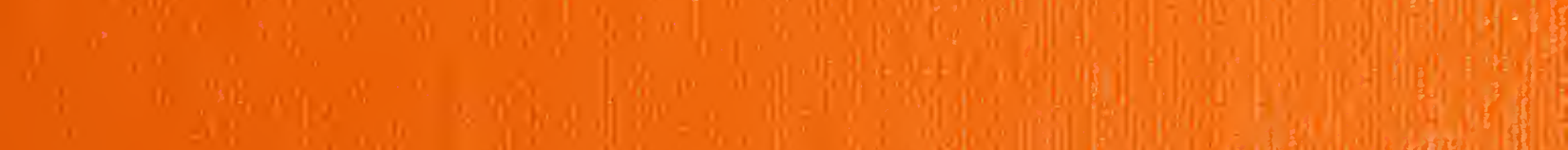

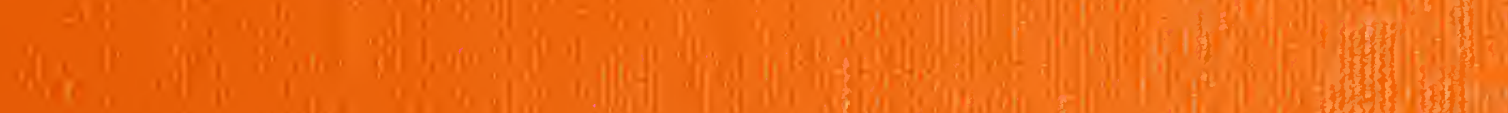

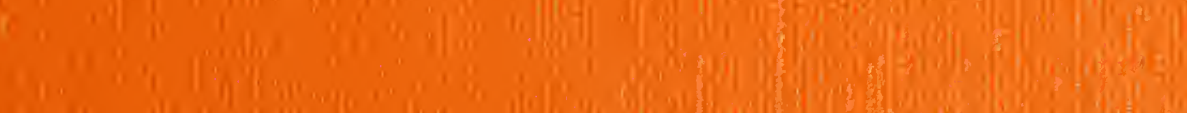
(1) (1)

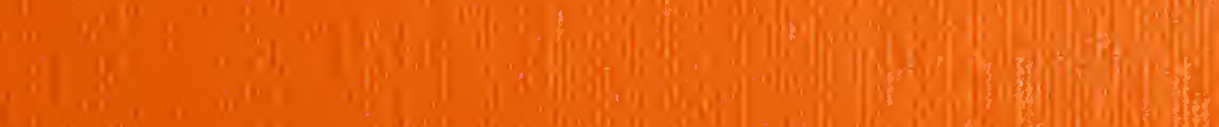







\section{NBSIR 74.569 \\ Influence of Normal Alcohols on the Abrasive Wear of Glass}

S. M. Wiederhorn and D. E. Roberts

Inorganic Materials Division

Institute for Materials Research

National Bureau of Standards

Washington, D. C. 20234

July 1974

Interim Report for Period July 1, 1973 through June 30, 1974

Prepared for

Department of the Navy

Office of Naval Research

Arlington, Virginia 22217 

NBSIR 74-569

INFLUENCE OF NORMAL ALCOHOLS ON THE ABRASIVE WEAR OF GLASS

S. M. Wiederhorn and D. E. Roberts

Inorganic Materials Division

Institute for Materials Research

National Bureau of Standards

Washington, D. C. 20234

July 1974

Interim Report for Period July 1, 1973 through June 30, 1974

Prepared for

Deparimen: of the Navy

Office of Naval Research

Arlington, Virginia 22217

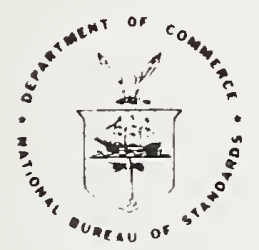

U. S. DEPARTMENT OF COMMERCE, Froderick B. Dent, Secretary NATIONAL BUREAU OF STANDARDS, Richard W. Roberts, Director 



\section{ACSIRACT}

Wormal alcohols vere used as cutting fluids in a study of friction and wear of soda lime silicate glass against silicon carbide. Abrasion surfaces were 600 grit silicon carbide paper and a roughened plate of hotpressed silicon carbide. As the alconol chain length increased, the coefficient of friction decreased. This result was attributed in part to better lubrication of the abrading surfaces by the long chain length alcohols. The wear rate and the coefficient of friction were strongly dependent on pullout of carbide grains from the silicon carbide paper. Tear on fresh abrasive paper was independent of alcohol chain length. As the paper becomes used, long chain lengti alcohols were more effective cutting fluids. On the silicon carbide plate, the wear rate decreased in a non-linear fashion as the alcohol chain length increased. For all conditions, the highest wear rate and coefficient of friction were obtained in water. Jata are explained in terms of classical theories of friction and wear. 



\section{Introduction:}

Abrasive finishing is an important fabrication technique that is used in the manufacture of optical glass and precision ceramic components. In this technique, fine-grained particles of diamond, aluminum oxide, or silicon carbide are abraded against the ceramic component to obtain desired dimensions and surface finish. The technique is used to improve strength and optical clarity of glass and to obtain the close tolerances necessary in applications such as gas bearings, ceramic seals, roller bearings and spark plugs. Since abrasive finishing is an expensive process (often accounting for 90 percent of the cost of the finished product) there is a great economic incentive to improve grinding efficiency.

One way of increasing grinding efficiency is by the development of superior cutting fluids specifically designed to increase grinding rates. Fluid design for comminution and drilling has been extensively studied and specific cutting fluids have been found to enhance these processes. ${ }^{1}$ Recently, Westwood and his colleagues found that the drilling rate of soda lime silicate could be enhanced by a factor of $\sim 20$ over that in water by using heptyl alcohol as a cutting fluid ${ }^{2}$, (figure $1 c$ ). Although other alcohols also enhanced the drilling rate, the effect was not as dramatic as that obtained in heptyl alcohol. Considering the effectiveness of heptyl alcohol as a drilling agent, it was felt that this alcohol might be equally effective as a cutting fluid 
in abrasive processes. Consequently, a study was conducted to determine the role of nurmal alcohols on the abrasive wear of soda lime silicate glass. The study included friction and wear measurements on silicon carbide surfaces, a characterization of the wear surfaces by microscopic techniques, and an analysis of the data in terms of theoretical models of friction and wear.

\section{Experimental Procedure:}

The coefficient of friction was measured by using a "drag" type of apparatus (figure 2). One-quarter inch precision ground soda lime silicate glass spheres (sphericity $2.5 \times 10^{-5}$ inches; diameter $\pm 10^{-4}$ inches) were mounted rigidly in a brass holder that permitted one end of the sphere to slide on an abrasive disk rotating at $100 \mathrm{rpm}$. The holder was mounted on a pivot arm that supported a fixed mass (either 100 or $375 \mathrm{~g}$ ) located directly over the glass sphere. The other end of the pivot arm was attached to a load cell that was used to measure the friction force. The abrasive surfaces were 600 grit silicon carbide abrasive paper, or a hot pressed silicon carbide plate that had been roughly ground using 45 micron diamond paste. Lateral displacement of the pivot arm by means of a precision screw permitted multiple wear track studies to be conducted.

Rates of wear were determined from the size of the flat that formed on the glass sphere during each wear experiment. The wear volume was calculated from equation (1)

$$
V=\frac{1}{3} \pi\left(R-\sqrt{R}^{2}-r^{2}\right)^{2}\left(2 R+\sqrt{R^{2}-r^{2}}\right),
$$

where $\Omega$ is the sphere radius and $r$ is the flat radius. 
The wear rate (the volume, V, lost after sliding a distance, $\mathrm{x}$, under a load, L) was calculated from equation (2)

$$
\mathrm{V} / \mathrm{xL}=\mathrm{V} / \mathrm{L} \pi \mathrm{D} t \mathrm{v}
$$

where $\mathrm{D}$ is the diameter of the wear track; $\mathrm{L}$ is the weight: $\nu$ is the rotational frequency of the disk (100 rpm in this study); and $t$ is the abrasion time.

rhe radius of the wear flat was measured either from photomicrographs of the wear surface, or by using a traveling microscope. When the wear flat was elliptical rather than round (observed mainly on the abrasive papers) an average of the maximum and minimum radius was used for the calculation.

The friction and wear studies were conducted by the following procedure: a sphere was placed in the holder, the pivot arm was balanced, and a weight was placed on the holder. The rotational speed of the disk was set, and the abrasion surface was flooded with water or a normal alcohol before placing the sphere on the rotating disk. The disk was continuously flooded during the entire duration of each experiment (lasting from 30 to 300 seconds). The alcohols used for the study ranged from rnethyl alcohol (carbon chain length, $n$, equals 1 ) to dodecyl alcohol $(n=12)$, with the exception of nonyl $(\mathrm{n}=9)$ and unedecyl $(\mathrm{n}=11)$ alcohols. In addition, water alcohol mixtures were studied for ethyl and butyl alcohol.

3. Experimental Results:

3.1 Friction Measurements--Silicon Carbide Paper

Results from the friction studies on the 600 grit silicon carbide 
paper are shown in figure 3. The average value of the coefficient of friction measured at the start of each experiment is given by the closed circles while the value measured after 30 seconds of abrasion is given by open circles. For all fluids studied, the coefficient of friction decreased during the 30 second abrasion period. The decrease appeared to be exponential, the coefficient of friction approaching a limit value after a long period of abrasion. Both the initial and final values of the coefficient of friction decreased linearly as the alcohol chain length increased. The value for water was slightly above the projected lines for the alcohols. After 30 seconds of abrasion, the coefficient of friction was approximately one-half of the initial value, with the apparent exception of water which was two-thirds of the initial value.

\section{2 Friction Measurements--Silicon Carbide Plate}

The friction data obtained on the silicon carbide plate are summarized in figure 4. The average value of the coefficient of friction, $\mu$, is given by closed circles for the start of each run and by open circles after three minutes of abrasion. For the alcohols, the coefficient of friction decreased during the abrasion period. The decrease appeared to be exponential approaching a constant value for long periods of abrasion. The decrease in the coefficient of friction during the three minute abrasion period ranged from approximately 20 to 40 percent of the initial value depending on the alcohol. In water, the coefficient of friction increased during the three minute abrasion period. Here too the increase appeared to be exponential approaching a constant value of long periods of abrasion. The increase was typically 50 percent of the initial value during the three minute abrasion period, and severe stick-slip was observed after approximately one minute of abrasion. 
In the alcohols, the coefficient of friction depended on the alcohol chain length, generally decreasing with increasing chain length. However, as shown in figure 4, the decrease was not 1inear. The initial value of the coefficient of friction decreased in an irregular manner as the chain length increased from $\mu \approx 0.41^{-}$for methyl alcohol to $\mu \approx 0.21$ for dodecyl alcohol. After three minutes of abrasion, the coefficient of friction still depended on alcohol chain length, but the dependence was not as great as for the initial values. In addition, values for ethyl and butyl alcohols were anomalously high.

The amount of water in the alcohols strongly influenced the friction behavior. By adding water, 1 percent by volume, to either ethyl or butyl alcohol, the friction behavior could be modified so that the coefficient of friction neither decreased or increased with abrasion time. The addition of more than one percent water resulted in a coefficient of friction that increased with abrasion time, whereas less than 1 percent water resulted in a coefficient of friction that decreased with time. The coefficient also depended on the surface condition of the glass and the silicon carbide substrate as could be demonstrated by changing either the wear track or the glass sphere during the abrasion period. In either case, the coefficient of friction would change back to its value at the start of the experiment.

\subsection{Wear Measurements--Silicon Carbide Paper}

The rate of wear of glass on silicon carbide abrasive paper (figure 5) depended on the condition of the abrasive paper. As is evident by comparing figures $5 \mathrm{a}$ and $5 \mathrm{~b}$, wear on a new track was always greater than wear on a used track. Depending on the alcohol chain length, the wear rate on a used track decreased by a factor of from 2 to 10 . This decrease in the wear rate was 
greatest for the short chain length alcohols and least for the water and long chain length alcohols. As will be discussed in section 4.1, this de-crease in wear rate results from grain pullout from the abrasive paper. The effect of alcohol chain length on the wear rate is shown in figure $5 a$ for fresh abrasive paper. The wear rate in water is $7.9 \times 10^{-12} \mathrm{~m}^{2} / \mathrm{ir}$; the wear rate in the alcohols $\left(\sim 4 \times 10^{-12} \mathrm{~m}^{2} / \mathrm{N}\right)$ is apparentiy independent of chain length. By contrast, a strong dependence of wear rate on alcohol chain length is obtained for multiple runs on a single wear track (figure 5b). Now the wear rate in the short chain length alcohols is approximately one third that found for the long chain length alcohols, indicating that the cutting effectiveness of the abrasive paper is maintained better in the long chain length alcohols than in the short chain length alcohols. However, the highest wear rates on a used track are obtained in water, indicating that the cutting effectiveness of abrasive paper is best in water.

\subsection{Wear Measurements--Silicon Carbide Plate}

The wear studies on the silicon carbide plate are depicted in figure 6. In figure 6a, the wear track was changed every 10 seconds to approximate a continuous exposure to a fresh wear surface, while in figure $6 \mathrm{~b}$ a single wear track was used for a period of three minutes. Large differences are observed in these two types of studies. In the multiple wear track study, the wear rate is higher and is strongly dependent on alcohol chain length. The wear rate in water $\left(\sim 2.1 \times 10^{-12} \mathrm{~m}^{2} / \mathrm{N}\right)$ is 
greater than that observed in the alcohols. In addition, plateaus at $\sim 0.9 \times 10^{-12} \mathrm{~m}^{2} / \mathrm{N}$ were observed for the short chain length alcohols $(\mathrm{n}=2$ through 5) and at $\sim 0.4 \times 10^{-12} \mathrm{~m}^{2} / \mathrm{N}$ for the long chain length alcohols ( $n=8$ through 12 ). A rapid change in the wear rate was observed between chain lengths 5 and 8 .

In the single wear track study (figure 6b), the wear rate was again highest in water $\left(\sim 0.86 \times 10^{-12} \mathrm{~m}^{2} / \mathrm{N}\right)$. In methyl alcohol the wear rate $\left(\sim 0.45 \times 10^{-12} \mathrm{~m}^{2} / \mathrm{N}\right)$ was less than in water, but greater than in the remainder of the alcohols. For chain lengths ranging from 2 to 10 the wear rate decreased linearly from $\sim 0.24 \times 10^{-12} \mathrm{~m}^{2} / \mathrm{N}$ for ethyl alcohol $(\mathrm{n}=2)$ to $\sim 0.12 \times 10^{-12} \mathrm{~m}^{2} / \mathrm{N}$ for decyl alcohol $(\mathrm{n}=10)$.

\subsection{Microscopic Wear Surfaces}

In order to elucidate the mechanisms of wear, the wear surfaces formed during the abrasion process were studied by optical and scanning electron microscopy (SEM). In these studies it was possible to estimate: the type of surfaces formed; the number of contact points at the abrading surfaces; the roughness of the abrading surfaces both before and after abrasion; and the role of plastic flow and fracture in the wear process.

\subsubsection{Silicon Carbide Papers}

Examination of the fresh silicon carbide paper (figure $7 \mathrm{a}$ and $7 \mathrm{c}$ ) reveals angular carbide particles imbedded in a plastic matrix. Most of the particles have sharp cutting edges which should be effective in cutting the glass if favorably oriented. During the abrasion process many of these particles are torn free from the plastic matrix leaving behind holes in the matrix (figure $7 \mathrm{~b}$ and $7 \mathrm{~d}$ ). This loss of cutting points depends on the lubricant used in the abrasion process. More cutting points are lost when 
short chain length alcohols are used than when long chain length alcohols are used. Since the most effective cutting points are expected to be lost during abrasion (because the force on these points is high), this observation qualitatively explains the decrease in the wear rate, and the dependence of the wear rate on the alcohol chain length (figure 5b) for the used tracks.

Optical studies of the wear surfaces are consistent with the structure of the silicon carbide paper and the loss of cutting efficiency as silicon carbide grains are torn from the paper. Wear surfaces appear to be formed mainly by a plastic cutting process. During the first few millimeters of motion, plastic flow is indicated by sharply defined grooves left in the surface of the glass (figure $8 a$ ). Sometimes these grooves are associated with cracks that lay parallel to the grooves. However, most often the grooves are crack free as evidenced by the fact that etching the surface with HF gives no indication of general crack formation. Approximately 60 points (over an area $\sim 0.8$ to $3 \mathrm{~mm}^{2}$ ) were in contact with the glass surface during abrasion. Thus, the average vertical load on the carbide grains was $\sim 1.7 \mathrm{~g}$ for the $100 \mathrm{~g}$ mass used in these experiments. The groove depths, determined by an optical interferometry study ranged from between $\sim 0.03$ and $0.4 \mu \mathrm{m}$; the groove widths ranged from less than $1 \mu_{\mathrm{m}}$ to $\sim 2 \mu_{\mathrm{m}}$. Assuming that the grooves were triangular in cross section, the angle between the wear flat and the groove surface, $\theta$, was estimated from a histogram of the ratio of the groove depth 
to width. * The mean value of $\theta$ was $\sim 18$ degrees, which corresponds to a cutting asperity angle of $\sim 144$ degrees. Although this asperity angle is within the range measured by Mulhearn and Samuels, ${ }^{3}$ it is considerably greater than that expected from the appearance of the SEM photomicrographs in figure 7 or from the way abrasive papers are made (electrostatic fields are used to align the particles so that sharp ends point out of the paper). As a wear flat develops on the glass spheres, the grooves that formed during the first few centimeters of motion overlap, leaving behind a relatively rough surface (figure 9a) with grooves ( $0.5 \mu \mathrm{m}$ deep) that are similar in appearance to those formed in metals by abrasive paper. These grooves were formed by multiple passes of individual cutting points over the glass since each large groove had a jagged cross section consisting of several finer grooves. After 30 seconds of abrasion, a smoother surface is formed due to the loss of cutting points from the abrasive paper (figure 9b).

\subsubsection{Silicon Carbide Plate}

Scanning electron micrographs of the silicon carbide plate revealed a rough surface containing $\sim 2 \mu \mathrm{m}$ grains (figure 10 ). As indicated by a profilimeter trace, and by examination with an optical microscope, the surface of the plate contained asperities that were separated by distances that ranged from 50 to $200 \mu \mathrm{m}$. The cutting edges of the silicon carbide grains did not seem to be as sharp as those of the paper. The

\footnotetext{
* Because the resolution of the optical microscope is $\sim 1 \mu \mathrm{m}, \theta$ was determined on scratches that were wider than $1 \mu \mathrm{m}$.
} 
asperity angle (measured from a profilimeter trace) ranged between 160 and 170 degrees $\left(5^{\circ}<\theta<10^{\circ}\right)$.

During the wear experiments, the contact asperities became coated with wear debris (figure 11). The amount of debris that collected depended on the lubricant used for the study. The greatest amount formed in water; lesser amounts formed in the low chain length álcohols; and hardly any formed in the long chain length alcohols. Although the debris could not be removed by scrubbing with a brush, it could be easily removed by etching with HF or by stripping with celluloid replicating film. After removal of the debris, wear flats could be observed on the silicon carbide plate, indicating that even though the hardness of silicon carbide $\left(2500 \mathrm{Kg} / \mathrm{mm}^{2}\right)$ is much greater than that of glass $\left(500 \mathrm{Kg} / \mathrm{mm}^{2}\right),{ }^{4}$ mutual wear of the glass and silicon carbide had occurred. The wear flats were readily apparent for the short chain length alcohols and water, but did not develop in the long chain length alcohols. For multitrack experiments on the silicon carbide plate, a change in wear mechanism is clearly indicated by a microscopic examination of the wear surface (figure 12).' In water (figure 12a), the entire surface is covered by a network of small cracks and pits suggesting that material removal is primarily by fracture. In low chain length alcohols ( $\mathrm{n} \leq 5$ ) the surface is also covered with pits, but the density of pits is not as great as in water (figure 12b). This difference in pit density probably accounts for the lower wear rate obtained in the alcohols. Wear is still 
primarily by chipping in the alcohol, but not as many chips are formed. *

In the long chain length alcohols, the wear surfaces are smooth and contain only a few large pits (figures $12 \mathrm{c}$ and $12 \mathrm{~d}$ ). The smooth appearance of the wear surface suggests that the wear process has changed from one of chipping to one of plastic flow. Between alcohols of chain lengths 5 and 7 , the change from a heavily pitted to a relatively smooth surface corresponded to the observed decrease in wear rate (figure 6a).

For wear studies on a single track, microscopic examination of the glass surface indicates that the initial stage of wear is by plastic flow, regardless of the test environment. During the first $3 \mathrm{~mm}$ of sliding (figure 8b), shallow grooves were left in the glass sphere. The grooves ranged between 1 and $5 \mu \mathrm{m}$ in width, and between 0.03 and $0.3 \mu \mathrm{m}$ in depth. An asperity angle of approximately 175 degrees $\left(\theta \sim 2.6^{\circ}\right)$ was estimated from measurements of the ratio of groove depth to width. The number of asperities contacting the glass surface was $\sim 60$ for the silicon carbide plate (the same as for the abrasive paper); the average load on each point was $\sim 6 \mathrm{~g}$ for the $375 \mathrm{~g}$ mass used in these studies. The grooves formed in the glass by the plate (figure $8 b$ ) were not as smooth as those formed by the paper. The groove structure resulted from the fact that

\footnotetext{
* Water dissolved in the low chain length alcohols may play an important role in the chipping process since the addition of only 1 volume percent alcohol to either ethyl or butyl alcohol results in a wear surface that is indistinguishable from that formed in water.
} 
each asperity contained several grains each of which left a mark in the glass. Etching of these shallow grooves gave no indication of crack formation during the early stage of the wear process. After about $1 \mathrm{~cm}$ of sliding,the individual grooves overlap to produce a relatively smooth wear surface. In water, fracture commences after approximately $3 \mathrm{~cm}$ of sliding (figure 13a), and after the glass sphere has traveled $10 \mathrm{~cm}$ on the silicon carbide block, the wear process is almost entirely by chipping. As the wear process continues (on the same track) the surface pits fill up with glass debris (figure 13b) which can be easily removed by an etch of $\sim 5 \mathrm{sec}$ in 15\% HF. After 2 to 3 minutes of abrasion, wear debris cushions the glass sphere preventing full contact between the glass sphere and the silicon carbide plate. The wear mechanism then changes back to a plastic flow process, resulting in a smooth wear surface (figure 13c) that is largely unaffected by an $\mathrm{HF}$ etch (figure 13d). In the short chain length alcohols, the development of the wear surface follows a course similar to that of water.

In the long chain length alcohols the wear process occurs by plastic flow in both the single and multitrack experiments. Glass wear surfaces are smooth (figure 14) and surface pitting, due to fracture, occurs only at isolated points on the wear surface. Plastic flow as a mechanism of wear is also indicated by the fact that etching in $\mathrm{HF}$ gives no evidence of crack formation on the wear surface.

4. Discussion of Results

4.1 Comparison of Results with those of Westwood et al. The initial intent of this work was to test normal alcohols as 
cutting fluids for the abrasive wear of glass on silicon carbide in hopes of finding a superior fluid for this process. These hopes were based on earlier work by Westwood and his coworkers who found that drilling rates in soda lime silicate glass with diamond drills could be increased by a factor of $\sim 20$ by use of heptyl alcohol as a drilling fluid. ${ }^{2}$ The increased drilling rate was attributed to the effect of this alcohol on the surface charge of the glass. In heptyl alcohol, the surface charge of the glass is zero because glass has a zero zeta potential in this alcohol, 5 (figure 1a). Nestwood and coworkers proposed a mechanism (involving alkali ion migration) by which glass attains a maximum hardness in environments of zero surface charge. Hence drilling in heptyl alcohol occurs more readily because the glass is harder and is more easily fractured under pressure of the drill. In water or other alcohols that do not give a zero zeta potential for the glass, the drilling rate is lower because the glass is softer and does not fracture so easily. * In support of their theory, Westwood and coworkers showed that the hardness of glass reached a maximum in heptyl alcohol (figure $1 b$, hardness was measured on a pendulum sclerometer) ${ }^{2}$ Evidence of a minimum in the coefficient of friction in hepty1 alcohol (figure 1d, sapphire sliding on soda lime silicate glass) was also presented to support their theory. The minimum in the coefficient of friction for heptyl alcohol was attributed to increased hardness and consequently to reduced plastic flow during sliding. The results of the present paper do not display the same anomalous behavior observed by Westwood and coworkers. Friction on the silicon carbide

* This behavior should be reversed if drilling occurs by a flow rather than by a fracture mechanism. ${ }^{7}$ Now, the softer material gives a higher drilling rate. 
paper dropped continuously as the alcohol chain length was increased. Friction on the silicon carbide block showed anomalous behavior for the short chain length alcohols, but not for heptyl alcohol. Similarly, wear studies showed no anomalous behavior for heptyl alcohol, with the possible exception of the multitrack studies (figure 6a), which showed a decrease in the wear rate at heptyl alcohol. * This decrease in the wear rate probably cannot be explained solely by the effect of alcohol on the hardness of glass because of the accompanying change in wear mechanism from fracture to plastic flow. These differences in behavior suggest that the frictjon and wear mechanisms proposed by Westwood and his coworkers to explain their data are not directly applicable to the present set of data. Therefore this data will be discussed with reference to other more classical theories of friction and wear.

\subsection{Friction of Glass on Silicon Carbide}

The friction results of this paper can be explained by the theories proposed by Bowden and Tabor ${ }^{9}$ who expressed the frictional force, F, between. two bodies as the sum of a shearing force, $F_{S}$, and a ploughing force, $F_{p}$. The shearing force results from adhesive contact between the two abrading surfaces. To break the adhesive bonds, the softer of the two materials must

* A similar observation has been made by Swain et al. ${ }^{8}$ on polycrystalline aluminum oxide. However, here a minimum in the grinding, rate in aqueous solutions and normal alcohols was correlated with a zero zeta potential in these solutions. This minimum contrasted with a maximum in the drilling rate for the same solutions. Results were interpreted in terms of adsorption dependent flow and fracture of alumina. Differences in the type of surface formed by abrasion were also reported in this work。 
flow plastically when relative motion occurs between the two surfaces. Thus, the shearing force is determined mainly by the plastic shear strength, $\sigma_{s}$, of the softer of the two materials. The frictional force, $F_{S}$, can be estimated from this shear stress and the hardness of the softer material. ${ }^{4}$ The area of real contact between the two materials, $A$, is given by $A=L / p$, where $L$ is the vertical load and $\mathrm{p}$ is the hardness of the softer material. The shearing force is given by $F_{S}=\sigma_{S} A=\sigma_{S} L / p_{\text {. }}$ Therefore, the shearing contribution to the coefficient of friction, $\mu_{s}$, is given by $\mu_{S} \equiv F_{S} / L=\sigma_{s} / p$, which for many materials equals $1 / 6$. In the absence of lubrication, the coefficient of friction is usually larger than this theoretical value because the real area of contact is larger than $\mathrm{L} / \mathrm{p}$ once sliding occurs. ${ }^{4}$ For very smooth surfaces, the real contact area between the sliding bodies can be large enough to give values of the coefficient of friction as high as 10 . In the presence of lubricants, the value of the coefficient of friction can be much less than the theoretical value because lubricants reduce the real area of contact between the sliding surfaces. Plowing contributes to the coefficient of friction when the harder of the two sliding surfaces is rough. Then asperities of the harder surface dig into the softer one and additional force is required to move the asperities through the soft material. This force depends on the "sharpness" of. the asperities of the harder material. By assuming that the asperities can be modelled by a right angle cone having an angle $\theta$ at its base, Rabinowicz ${ }^{4}$ has shown that the plowing contribution to the coefficient of friction is given by $\mu_{p}=(1 / \pi) \tan \theta$. Kore generally $\mu_{p}=(1 / k) \tan \theta$, where $k$ is a form factor that depends on the shape of the asperities. 
$k$ ranges from $\sim 1 / 2$ for triangular pyramids to $\pi$ for right angle cones. $10 *$ Bowden and Tabor ${ }^{9}$ have noted that the plowing term does not in general depend on the presence of lubricants at the wear surface, but does depend on the geometry of the asperities. By combining the shear and plowing components, the following equation is obtained for the coefficient of friction:

$$
\mu=\sigma_{s} / p+(1 / k) \tan \theta
$$

This equation will be used to provide a semiquantitative explanation of the results of the present paper.

On silicon carbide paper, friction measurements are initially high because sharp asperities (high $\theta$ ) contribute a large plowing component to the friction force. During the wear process, the sharpest grains are torn from the paper, and the friction coefficient decreases because duller grains are left behind (thus reducing $\theta$ ). This explanation is consistent with the appearance of the wear surfaces of both the silicon carbide paper and the glass spheres. When sliding starts on a fresh wear track. the coefficient of friction is probably due to the combined effect of shearing and plowing. If the decrease in the coefficient of 0.2 (figure 3) can be attributed to a decrease to zero of the plowing component of the coefficient of friction, then (assuming $k=1)$ tan $\theta$ is calculated to be $\sim 0.2\left(\theta \simeq 12^{\circ}\right)$ which is within the range estimated in this paper and in the work by Mulhearn and Samuels ${ }^{3}$ and Goddard and Wilman. ${ }^{10}$

\footnotetext{
$*$

"In a detailed analysis of the effect of shape of indenting particle on the coefficient of friction, Goddard and Wilman 20 showed that the mean value of $1 / \mathrm{k}$ for triangular and square pyramids was $\sim 1$. Although their analysis provides a much more complete equation for the coefficient of friction, equation (3) is adequate for discussing the results of this paper.
} 
Coefficients of friction measured on the hot pressed silicon carbide plate are less than those measured on the abrasive paper because the contact asperities of the plate are not as large as those of the paper. If the decrease in the coefficient of friction $(\sim 0.07$ for the long chain length alcohols in figure 4) is attributed to plowing, then $\tan \theta \simeq 0.07\left(\theta \simeq 4^{\circ}\right)^{*}$. This estimate of $\tan \theta$ lies between that estimated from the profilimeter study ( $\tan \theta \simeq 0.13$ ) and that estimated from wear tracks on the glass ( $\tan \theta \simeq 0.046)$.

The decrease in the coefficient of friction with increasing alcohol chain length is probably due to lubrication of the wear surfaces by the alcohols. As the alcohol chain length increases, the alcohols cover the wear surfaces more effectively, thus reducing the area of real contact between the surfaces. Since the long chain length alcohols should be more effective lubricants than the short chain length alcohols, the coefficient of friction is expected to decrease as the alcohol chain length increases. This decrease in friction coefficient was observed in the present study, in the study by Hardy and Doubleday, 11 and in the work by Macmillan et al., confirming the general effect of alcohol lubrication.

In the work by Hardy and Doubleday ${ }^{11}$ the coefficient of friction was measured using polished glass sliders (watch glasses) on polished glass plates. The coefficient of friction decreased from $\mu \approx 0.68$ in methyl alcohol to $\mu \approx 0.45$ in

* This estimate of $\tan \theta$ depends on the value selected for $k$. A variation of $k$ from $\sim 1 / 2$ to $\sim 3$ results in a variation in the estimate of $\tan \theta$ from $0.1\left(\theta \simeq 6^{\circ}\right)$ to $0.6\left(\theta \simeq 30^{\circ}\right)$. Since $k=1$ gives a value of $\tan \theta$ that is consistent with other measurements of $\tan \theta, 3,10$ this value will be assumed for the remainder of the paper. 
unedecyl alcohol. This decrease of $\sim .23$ is similar to the decreases measured in the present study ( $\sim 0.16$ for SiC paper on a new track; $\sim 0.13$ for SiC paper after $30 \mathrm{sec}$ wear; $\sim 0.21 \mathrm{SiC}$ block in a multitrack experiment) suggesting that the relative effect of alcohol lubrication is the same for both studies. The large values of the friction coefficient measured by Hardy and Doubleday may be due, in part, to the large areas of real contact expected for the smooth surm faces used in their experiments. In the work by Macmillan et al., ${ }^{6}$ a sharp minimum in the coefficient of friction at $n=7$, was superimposed on the general decrease in friction coefficient (figure 1d). In their study the coefficient of friction decreased from $\mu \approx 0.75$ for methyl alcohol to $\mu \approx 0.16$ for dodecyl alcohol, with a value of $\mu \approx 0.18$ for heptyl alcohol. The total change in the friction coefficient, $\sim 0.69$, was approximately three times that observed in the present work or in the work by Hardy and Doubleday. Furthermore, the sharp minimum observed by Macmillan et al. for heptyl alcohol was not observed in the present work (Hardy and Doubleday did not use heptyl alcohol in their studies). The reasons for these differences in experimental results is not readily apparent, but may involve differences in the nature of the glass surfaces studied (fracture versus abraded surfaces), or differences in experimental technique (sapphire sliding on glass versus glass sliding on silicon carbide). The results of the present study also indicate a dependence of the coefficient of friction on the condition of the wear surface. For silicon carbide paper, pullout of the abrasive particles from the paper results in a large decrease of the coefficient of friction. This decrease is most pronounced in the short chain length alcohols which probably attack the adhesive bond between the silicon carbide particles and the abrasive paper. For the 
silicon carbide plate, glass residue accumulation at the cutting asperities and blunting of the cutting asperities during the abrasive process have a significant influence on the coefficient of friction. The effect of glass residue (probably in the form of a gel) is most apparent for the tests conducted in water. Here, the residue probably acted as a buffer between the glass and the silicon carbide cutting points. The residue must have been extremely viscous to account for the $\sim 20$ percent increase in the coefficient of friction. In alcohols, the residue did not affect the friction coefficient in the same way, suggesting a fundamentally different behavior of the friction process. In alcohols, the coefficient of friction seems to be affected more by the development of wear flats on the silicon carbide plate than by the accumulation of glass residue.

\subsection{Wear of Glass on Silicon Carbide}

\subsubsection{Mechanisms of Wear}

As discussed by Mulhearn and Samuels ${ }^{3}$ and by Rabinowicz, 4 abrasive wear of materials depends on the presence of asperities on the abrading surface and on the so-called "attack angle" between the asperities and the wear surface. Abrasive wear occurs when asperities dig into the wear surface, plowing the surface and removing material during sliding. As with friction, the amount of plowing depends on the "sharpness" of the contact asperities, sharper asperities resulting in a greater amount of wear. However, the angle between the asperities and the wear surface is also important. If the attack angle is large,then the wear rate is high because the contact asperities can cut material away from the wear surface in the same way that a cutting tool peels metals in lathe operations. If the attack angle is not large, then the contact asperities merely displace material on 
the wear surface, and wear rates are not as high. ${ }^{3}$ Mulhearn and Samuels have estimated 90 degrees as the critical attack angle for material removal. These ideas are expressed quantitatively by the following equation for the volume, $\mathrm{V}$, lost after sliding a distance, $\mathrm{x}$, under a load, $\mathrm{L}$ :

$$
\mathrm{V} / \mathrm{xL}=(\mathrm{f} \tan \theta) /(\mathrm{pk})
$$

$f$ is the fraction of points that participate in the cutting process; $\theta$ is the angle between the wear surface and the cutting points; $\mathrm{p}$ is the hardness; and $\mathrm{k}$ is a factor that depends on the geometry of the cutting asperities. As with the plowing component of the coefficient of friction, $k$ ranges in value from $1 / 2$ for triangular pyramids to $\pi$ for right angle cones.

Wear may also occur by mechanisms other than abrasion, including adhesion, corrosion, and fretting. In adhesive wear, material is lost from the wear surface by plastic flow which results when the two sliding surfaces adhere at contact points. The wear mechanism is identical to that which accounts for the shearing component of the coefficient of friction. Rabinowicz ${ }^{4}$. has derived the following equation for adhesive wear:

$$
\mathrm{V} / \mathrm{xL}=\mathrm{a} / 3 \mathrm{p}
$$

where $\mathrm{a}$ is the wear coefficient. Corrosive wear occurs when a corrosive species attacks the wear surface leaving behind corrosion products that are removed when the two surfaces rub together. Corrosive wear is believed to be a dominant feature in the preparation of polished glass surfaces. ${ }^{12}$ Wear by fretting involves the formation of cracks on the wear surface. ${ }^{12}$ Wear 
occurs by the propagation of these cracks so that wear particles are chipped from the wear surface.

\subsubsection{Abrasive Paper}

Abrasive wear was the dominant mechanism for material removal by the abrasive papers. As with metals, material removal was primarily by plastic cutting. The wear rate can be estimated from the theory derived by Mulhearn and Samuels ${ }^{3}$ (equation 4). In experiments on cold-drawn steel using a 500 gram mass, these investigators found that the proportion of abrasive particles, $f$, that cut the metal was 0.13 for fresh paper and 0.05 after 50 traverses on an $8 \mathrm{~cm}$ radius. ${ }^{*}$ The value of $\mathrm{p}$ for soda lime silicate glass is $\sim 5 \mathrm{x} 10^{9} \mathrm{~N} / \mathrm{m}^{2}$ $\left(500 \mathrm{Kg} / \mathrm{mm}^{2}\right)$. For $\mathrm{k} \simeq 1$, $\mathrm{f} \simeq 0.1$ and $\tan \theta=0.33$, a value of $6.6 \times 10^{-12}$ $\mathrm{m}^{2} / \mathrm{if}$ is calculated for the wear rate, $\mathrm{V} / \mathrm{xL}$. This value is close to those measured in the current study $\left(4-5 \times 10^{-12} \mathrm{~m}^{2} / \mathrm{N}\right.$ for the 30 second wear study in the alcohols and $7.9 \times 10^{-12} \mathrm{~m}^{2} / \mathrm{N}$ for the 30 second wear study in water). Considering the approximations necessary for this calculation (for $\mathrm{f}, \mathrm{k}$ and $\tan \theta$ ) the agreement between the predicted and measured values of the wear rate is satisfactory.

In the long chain length alcohols, wear on the silicon carbide plate was approximately $1 / 10$ that on the silicon carbide paper. This decrease in the wear rate can be attributed to the relativeiy biunt asperities that are present on the silicon carbide plate. As calculated from groove

\footnotetext{
* The conditions used by lulhearn and Samuels were not too different from those used in this study.
} 
measurements, $\tan \theta$ for the silicon carbide plate ( $\tan \theta \simeq 0.046$ ) was approximately a factor of 10 less than $\tan \theta$ for the silicon carbide paper ( $\tan \theta \simeq 0.33$ ). Assuming that the fraction of cutting points for the two wear surfaces was the same, a wear rate of $0.92 \times 10^{-12} \mathrm{~m}^{2} / \mathrm{N}$ is calculated from equation 4. This value is approximately twice that measured for the long chain length alcohols, ${ }^{*} \sim 0.4 \times 10^{-12} \mathrm{~m}^{2} / \mathrm{N}$.

In the short chain length alcohols, wear on the silicon carbide plate occurred mainly by fracture. The driving forces for the fracture arose from adhesive shear forces on the glass sphere. Numerous earlier studies have shown that, in glass, Hertzian type cracks form as a result of these shear forces. 12 Linking up of these cracks during the abrasion process accounts for the pits observed on the glass wear surface. Since water plays a major role in controlling crack growth in glass, ${ }^{13}$ it is probable that the amount of water in the alcohol governed fracture during abrasion. Furthermore, since water is relatively soluble in the short chain length alcohols and is easily absorbed from the air, fracture is also expected as the major wear mechanism in the short chain length alcohols. In the long chain length alcohols, fracture is not expected because water is relatively insoluble in these alcohols. Thus, the change in wear mechanism between amyl and heptyl alcohol can be qualitatively attributed to the amount of water in the alcohols. The detailed mechanism of crack formation and propagation during abrasion (the number of cracks, size, rate of formation) will not be covered in this paper.

* The estimated value of the wear rate is high probably because the estimated fraction of cutting points is high. One would expect the fraction of effective cutting points on the plate to be less than that on the abrasive paper. Agreement between theory and experiment would require that $f \simeq 0.05$ for the plate. 


\section{Summary:}

This paper presents the results of a study of the friction and wear of soda lime silicate glass on silicon carbide. Water and normal alcohols were used in these studies to determine the relative effectiveness of these liquids as cutting fluids. Wear surfaces studied were 600 grit silicon carbide abrasive paper and a hot-pressed SiC plate that had been ground on 45 micron diamond paste. Although the results are complicated, they can be interpreted in terms of the classical theories of friction and wear.

As expected from lubrication theory, the coefficient of friction for both the paper and the plate decreased as the chain length of the normal alcohol increased. Both plowing and adhesion contributed to the coefficient of friction. Plowing assumed a greater importance for silicon carbide abrasive paper than for the silicon carbide plate because of the sharp, irregular particles contained in the paper. Generally, as the abrasion time increased, the coefficient of friction decreased for both the paper and the plate. This result was attributed to particle pullout for the abrasive paper and to blunting of the contact asperities of the silicon carbide plate.

The wear rate data on the abrasive paper could be explained by current theories of abrasive wear. A theoretical estimate of the wear rate of glass on fresh abrasive paper was in close agreement with experimental measurements of the wear rate. The wear rate decreased as the abrasive paper was used because of particle pullout from the paper. This result was most apparent for the short chain length alcohols. 
For the silicon carbide plate, two mechanisms of wear were observed: chipping for the short chain alcohols; and plastic flow for the long chain alcohols. The chipping was influenced by the presence of water in the alcohols since the deliberate addition of small amounts of water greatly enhanced the amount of chipping. The wear rate was also influenced by the accumulation of wear debris at the contact asperities of the silicon carbide plate and by blunting of these asperities as a result of the wear process. In the present study, water was found to be the most effective cutting fluid for the abrasive wear of glass, regardless of test condition. This result differs from an earlier one by Westwood and his colleagues who found that heptyl alcohol was the most effective cutting fluid for drilling soda lime silicate glass. Other aspects of the present set of data also differ from those of Westwood et al. These differences suggest that the wear mechanisms proposed by Westwood at al. are not applicable to the present set of data. By contrast, the more classical theories of friction and wear are applicable because the present set of data can be readlly interpreted in terms of these theories. 


\section{References}

1. P. Somasundaran and I. J. Lin, "Effect of Nature of Environment on Comminution Prbcesses," Ind. Eng. Chem. Process Des. Develop. 11, 321-31 (1972)

2. A. R. C. Westwood, G. H. Parr, Jr., and R. M. Latanison, Amorphous Materials, John Wiley and Sons, New York, p 153 (1972).

3. T. O. Mulhearn and L. E. Samuels, "The Abrasion of Metals: A Model of the Process," Wear $\underline{5}, 478-98$ (1962).

4. E. Rabinowicz, Friction and Wear of Materials, John Wiley and Sons, New York (1965).

5. A. R. C. Westwood and N. H. Macmillan, The Science of Hardness Testing Am. Soc. Metals, Cleveland, Ohio, in press (1973).

6. iv. H. Yacmillan, R. D. Huntington and A. R. C. Westwood, "Chemomechanical Control of Sliding Friction Behavior in Nonmetals," J. Mat. Sci. $\underline{9}$, 697-706 (1974)

7. A. R. C. Westwood and R. M. Latanison, pp 141-153, in The Science of Ceramic Machining and Surface Finishing, NBS Special Publication 348, May 1972.

8. M. V. Swain, R. M. Latanison and A. R. C. Westwood, "EnvironmentSensitive Hardness and Machinability of Alumina," to be presented at the NSF Hard Materials Workshop, July 1974.

9. F. P. Bowden and D. Tabor, The Friction and Lubrication of Solids, Part I, Oxford at the Clarendon Press (1950). 
10. J. Goddard and H. Wilman, "A Theory of Friction and Wear During the Abrasion of Metals," Wear 5, 114-135 (1962).

11. W. B. Hardy and I. Doubleday, "Boundary Lubrication, The Paraffin Series," A100, 550 (1922).

12. L. Holland, The Properties of Glass Surfaces, Ch. 1, John Wiley and Sons, Inc., New York (1964).

13. S. M. Wiederhorn, pp. 731-742, in Corrosion Fatigue: Chemistry, Mechanics and Microstructure, National Association of Corrosion Engineers, Houston, Texas (1972). 
Figure 1. Variation of (a) $\zeta$ potential,,$^{5}$ (b) pendulum hardness, ${ }^{2}$ (c) rate of penetration with diamond studded bit, 2 and (d) coefficient of sliding friction 6 on soda lime silicate glass in water, toluene and $n$-alcohol environments. $i_{C}$ is the number of carbon atoms in the n-alcohol molecule.

Figure 2. Friction and wear apparatus

Figure 3. Friction measurements on silicon carbide abrasive paper (600 grit)

Figure 4. Friction measurements on the silicon carbide plate

Figure 5. Wear rate on silicon carbide abrasive paper (600 grit)

Figure 6. Wear rate on silicon carbide plate

Figure 7. Scanning electron micrographs of abrasive paper. (a) and (c) are new papers; (b) and (d) are wear tracks formed in methyl alcohol. The black areas of (b) and (d) are due to pullout of the silicon carbide grains.

Figure 8. Wear surfaces formed during the first few millimeters of sliding (a) abrasive paper and (b) silicon carbide plate

Figure 9. Development of the wear surface during abrasion on silicon carbide abrasive paper. (a) rough surface formed after $\sim 20 \mathrm{~cm}$ of sliding; (b) smoother surface formed after $\sim 1000 \mathrm{~cm}$ of sliding

Figure 10. Scanning electron micrograph of silicon carbide plate

Figure 11. Wear debris formed at the cutting asperities on the silicon carbide plate (ethyl alcohol as lubricant)

Figure 12. Wear surface of the glass spheres formed by abrasion against the silicon carbide plate. Track changed every 10 seconds to approximate continuous wear. (a) water, (b) butyl alcohol, (c) heptyl alconol, and (d) dodecyl alcohol.

Figure 13. Wear surface formed by abrading the soda lime silicate spheres against the silicon carbide plate in water. (a) after $\sim 3 \mathrm{~cm}$ of sliding, (b) after $\sim 100 \mathrm{~cm}$ of sliding (3 seconds), (c) after $\sim 6000 \mathrm{~cm}$ of sliding ( 5 minutes), (d) same as (c), but etched with H.F.

Figure 14. Wear surface formed by abrading the soda lime silicate glass spheres against the silicon carbide plate in decyl alcohol. (a) after $\sim 6 \mathrm{~cm}$ of sliding, (b) after $\sim 100 \mathrm{~cm}$ of sliding (3 seconds), (c) after $\sim 6000$ $\mathrm{cm}$ of sliding (5 minutes), (d) same as (c), but etched with $\mathrm{H}$. F. The large curved crack in (c) and (d) was not formed by the abrasion process. Cracks of this sort vere frequently observed in the as-received spheres. 


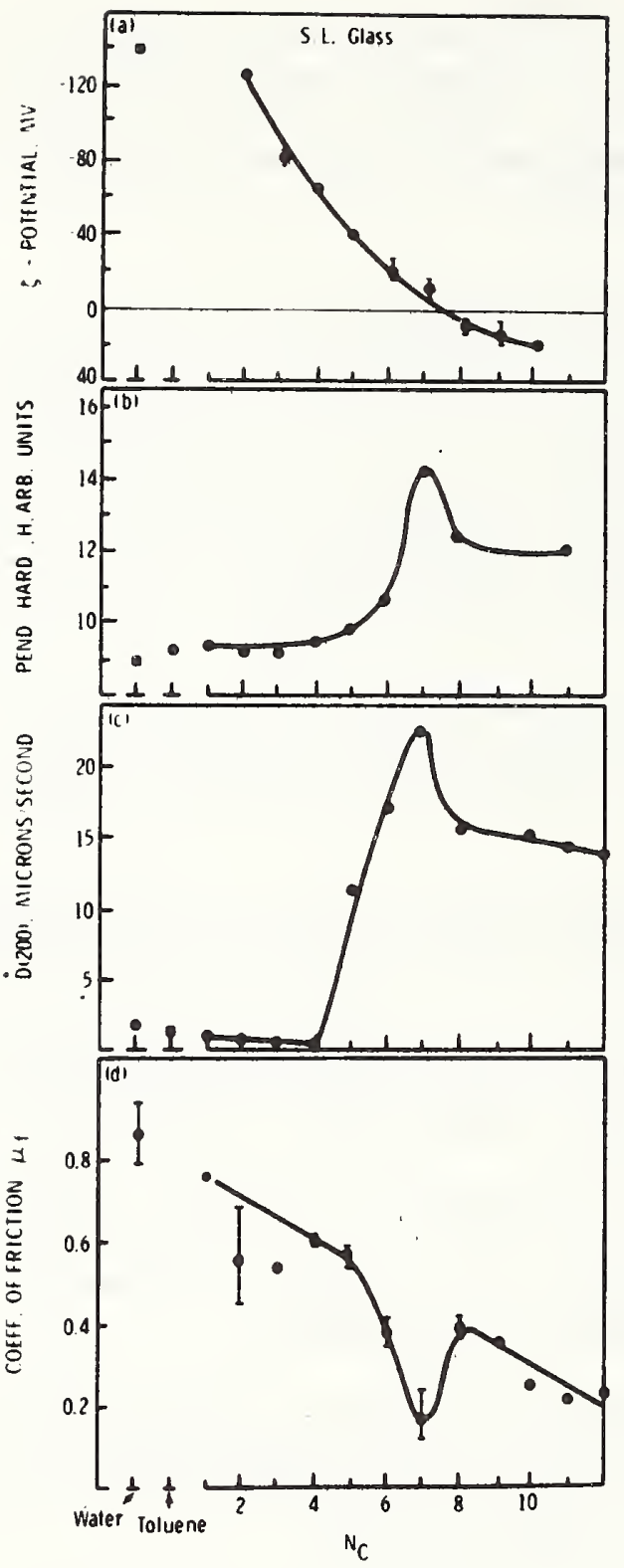

Fimure 1. Variation of (a) $\zeta$ potential, ${ }^{5}$ (b) penduium hardness, ${ }^{2}$ (c) rate of penetration with dianond studded bit, ${ }^{2}$ and (d) coefficient of sliding Friction ${ }^{6}$ on soda lime silicate glass in water, toluene and $n$-alcotol environents. $N_{C}$ is the number of carbon atoms in the n-alcohol molecule. 


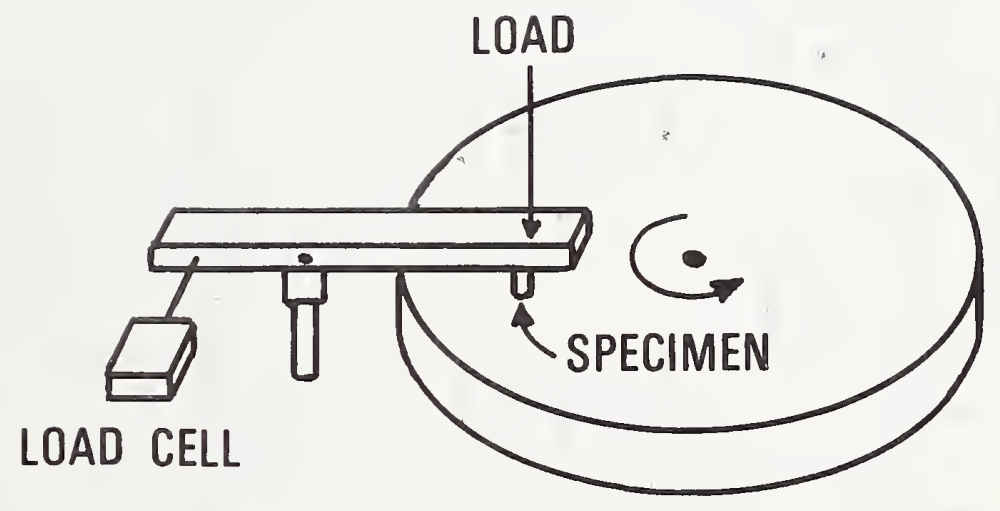

Figure 2. Friction and wear apparatus 


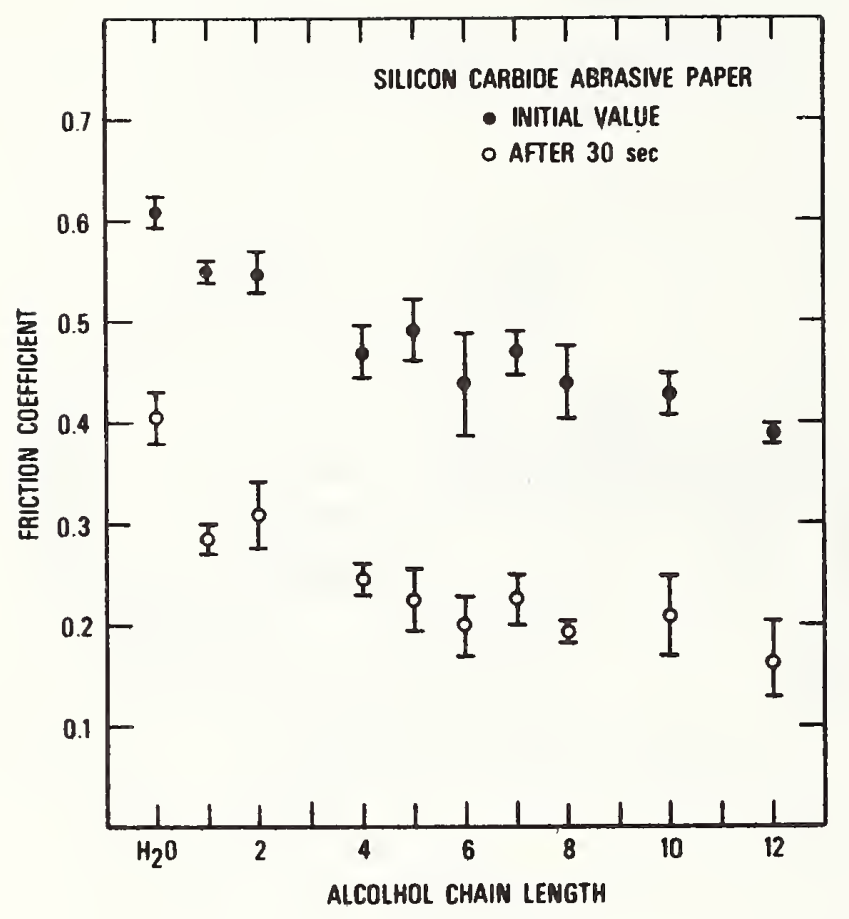

Figure 3. Friction measurements on silicon carbide abrasive paper (600 grit) 


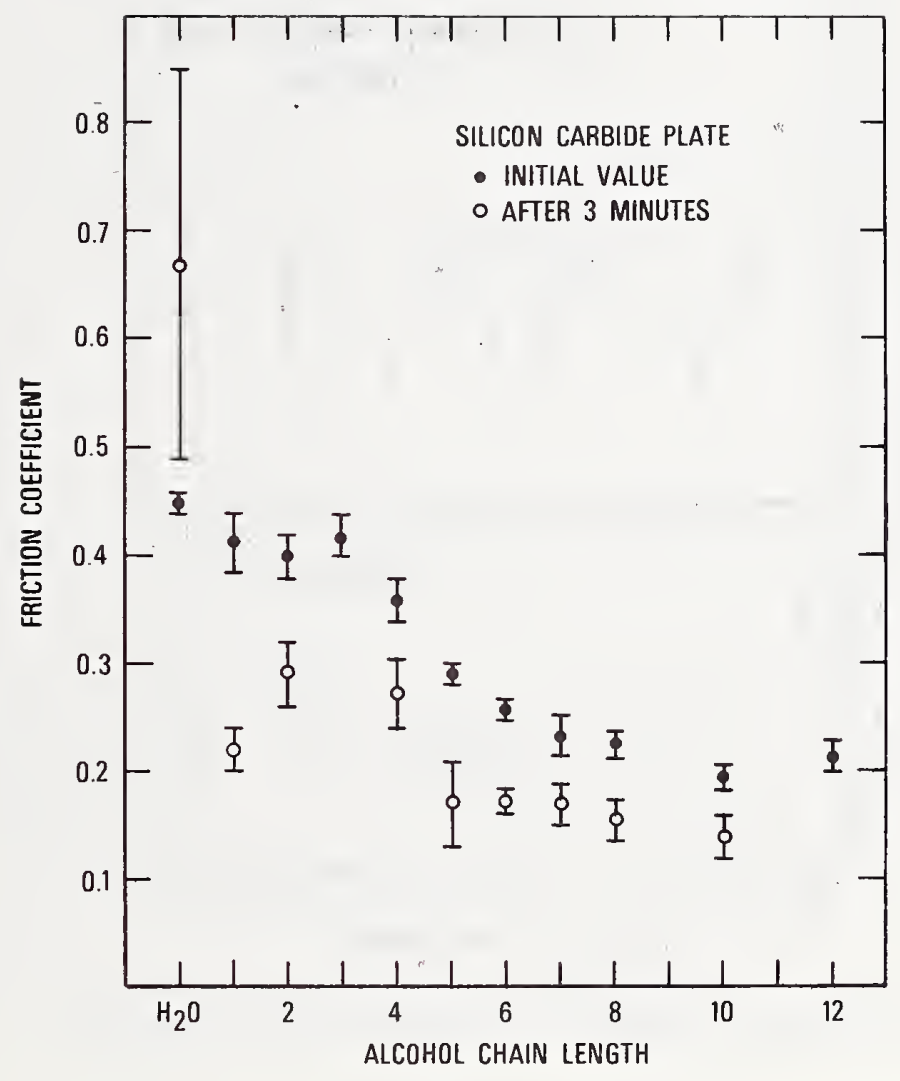

Figure 4. Friction measurements on the silicon carbide plate 


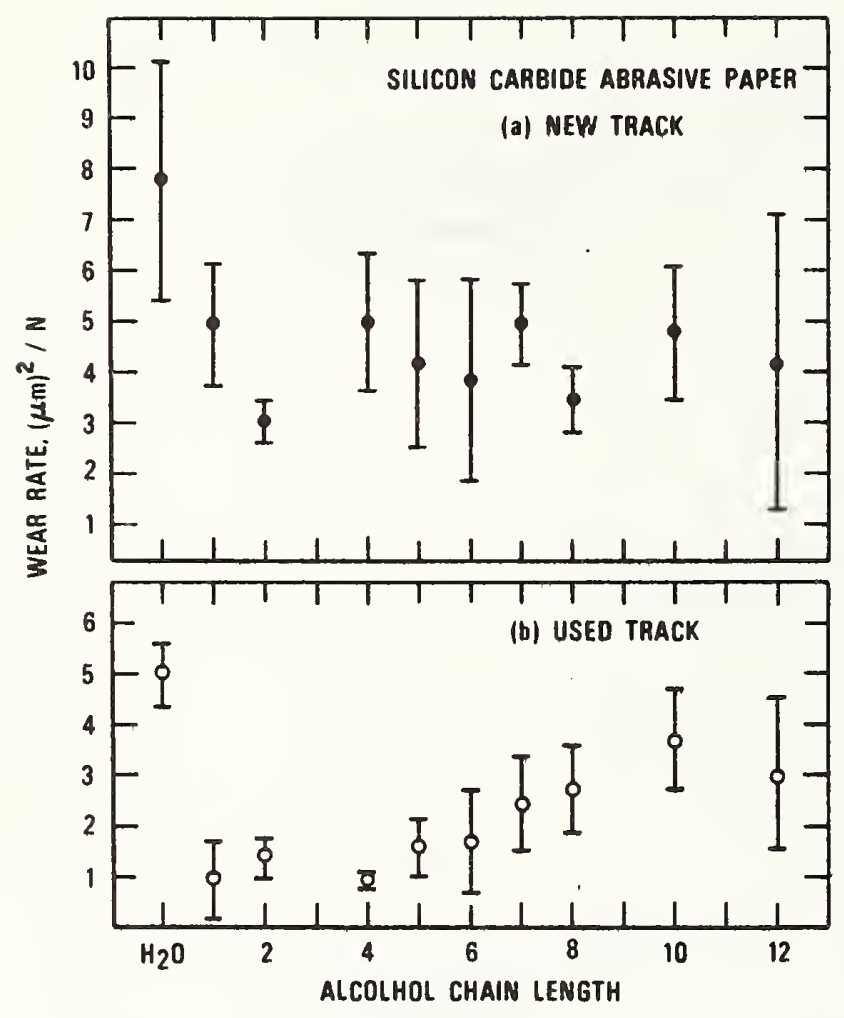

Figure 5. Wear rate on silicon carbide abrasive paper (600 grit) 


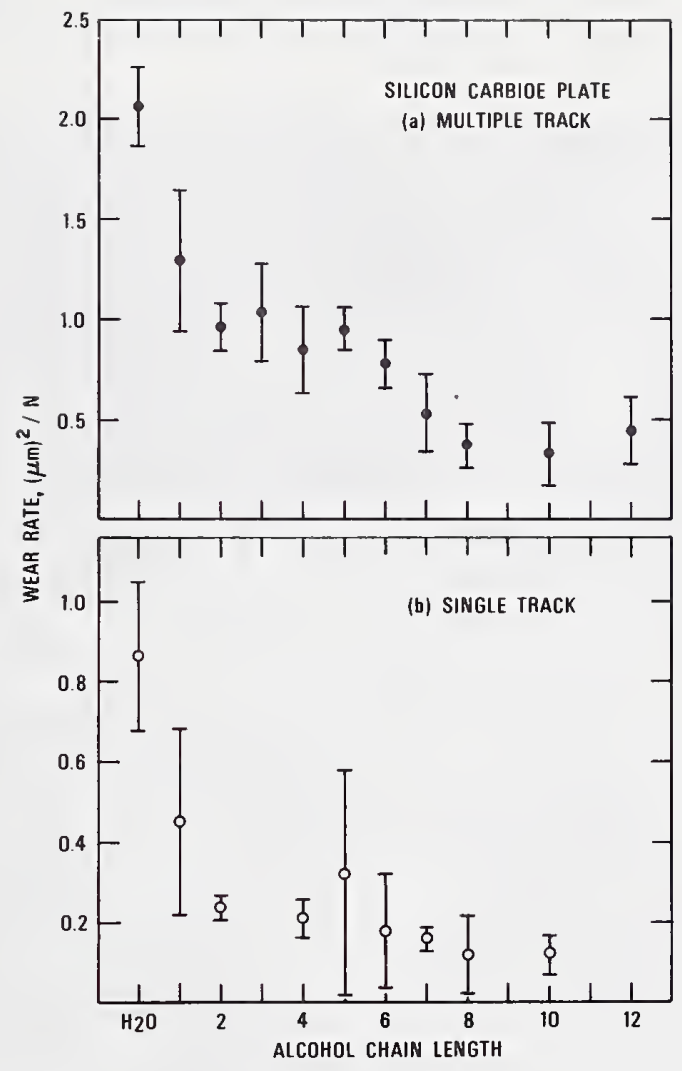

Figure 6. Wear rate on silicon carbide plate 


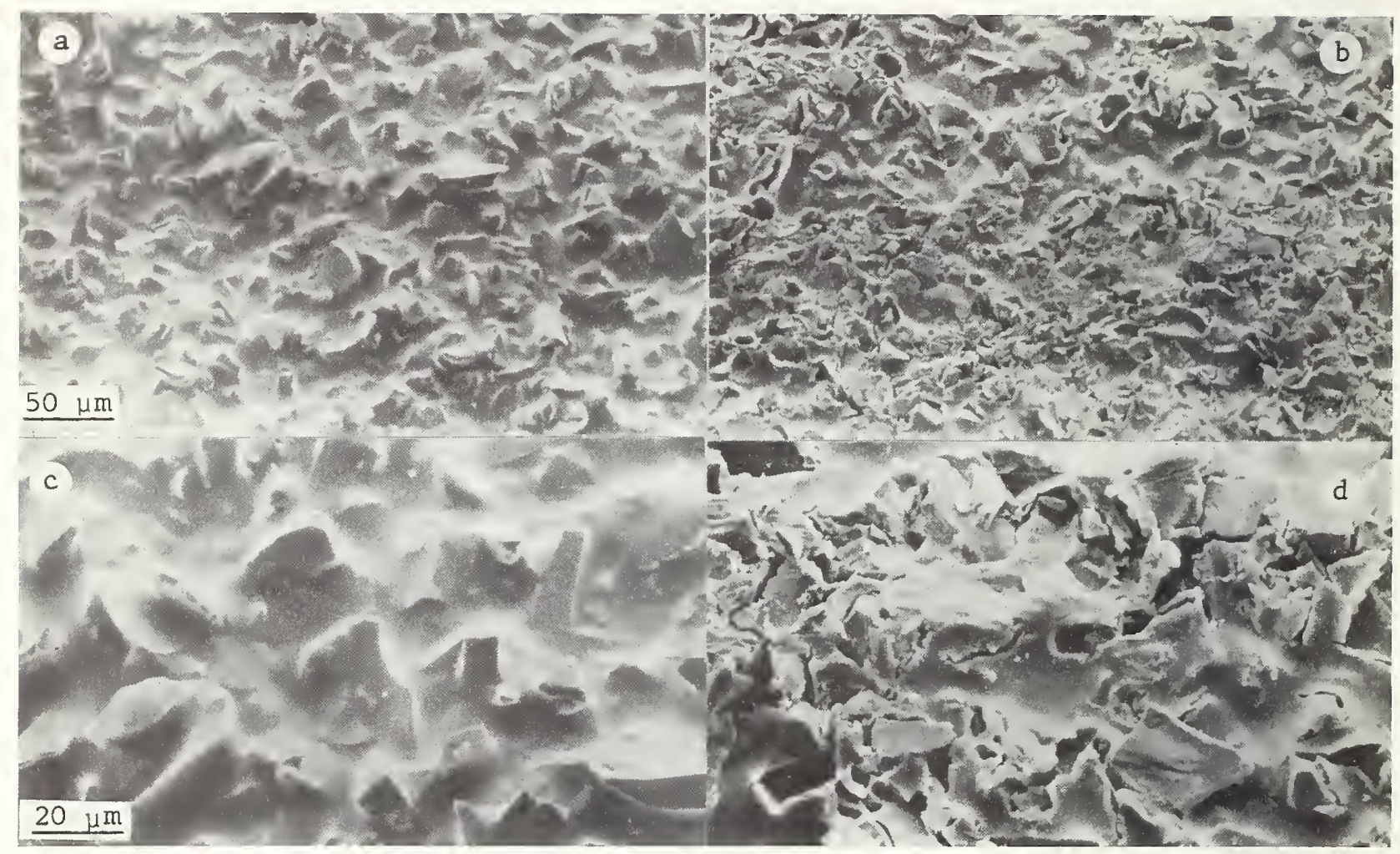

Figure 7. Scanning electron micrographs of abrasive paper. (a) and (c) are new papers; (b) and (d) are wear tracks formed in methyl alcohol. The black areas of (b) and (d) are due to pullout of the silicon carbide grains. 


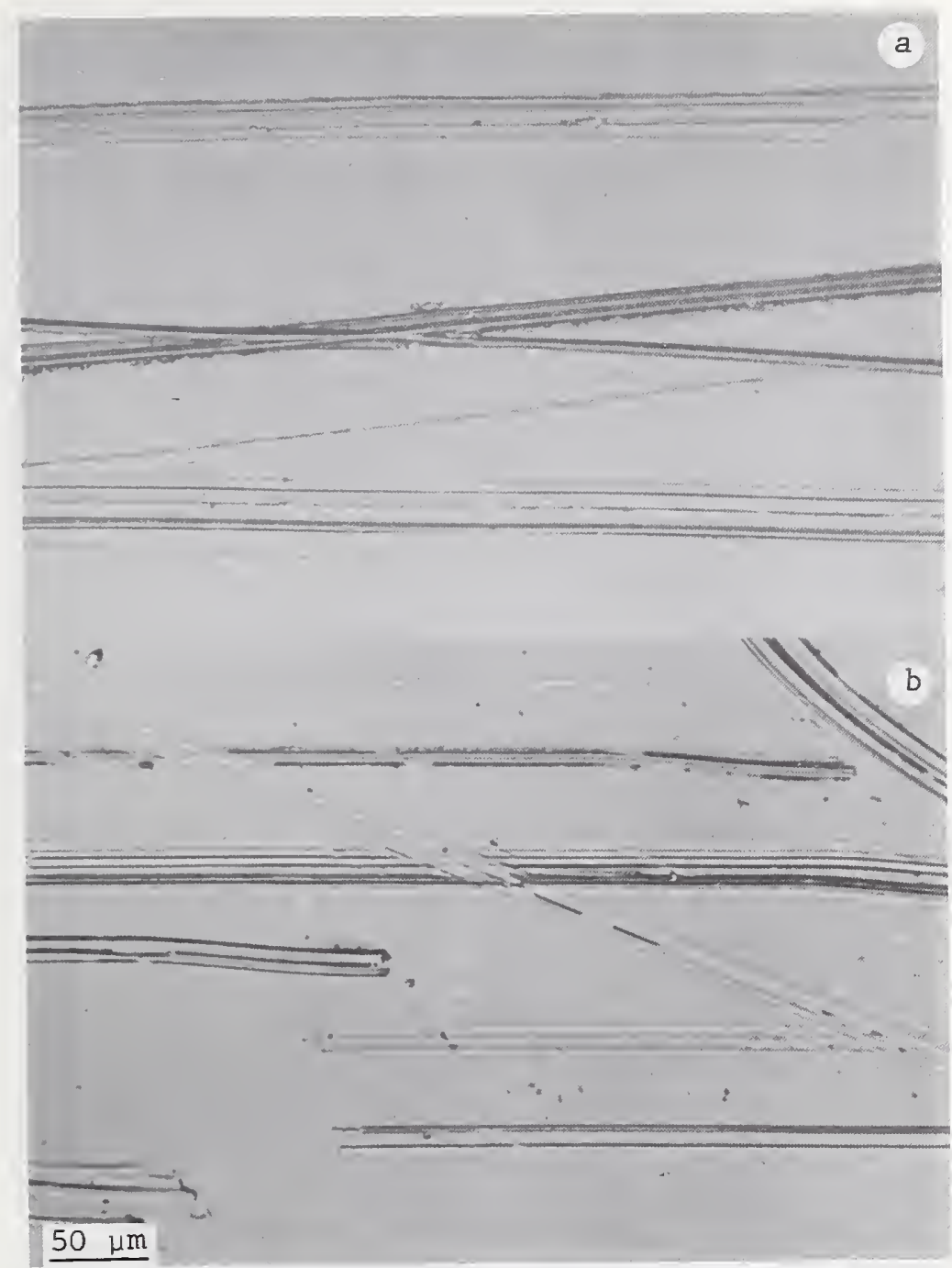

Figure 8. Wear surfaces formed during the first few millimeters of sliding (a) abrasive paper and (b) silicon carbide plate 


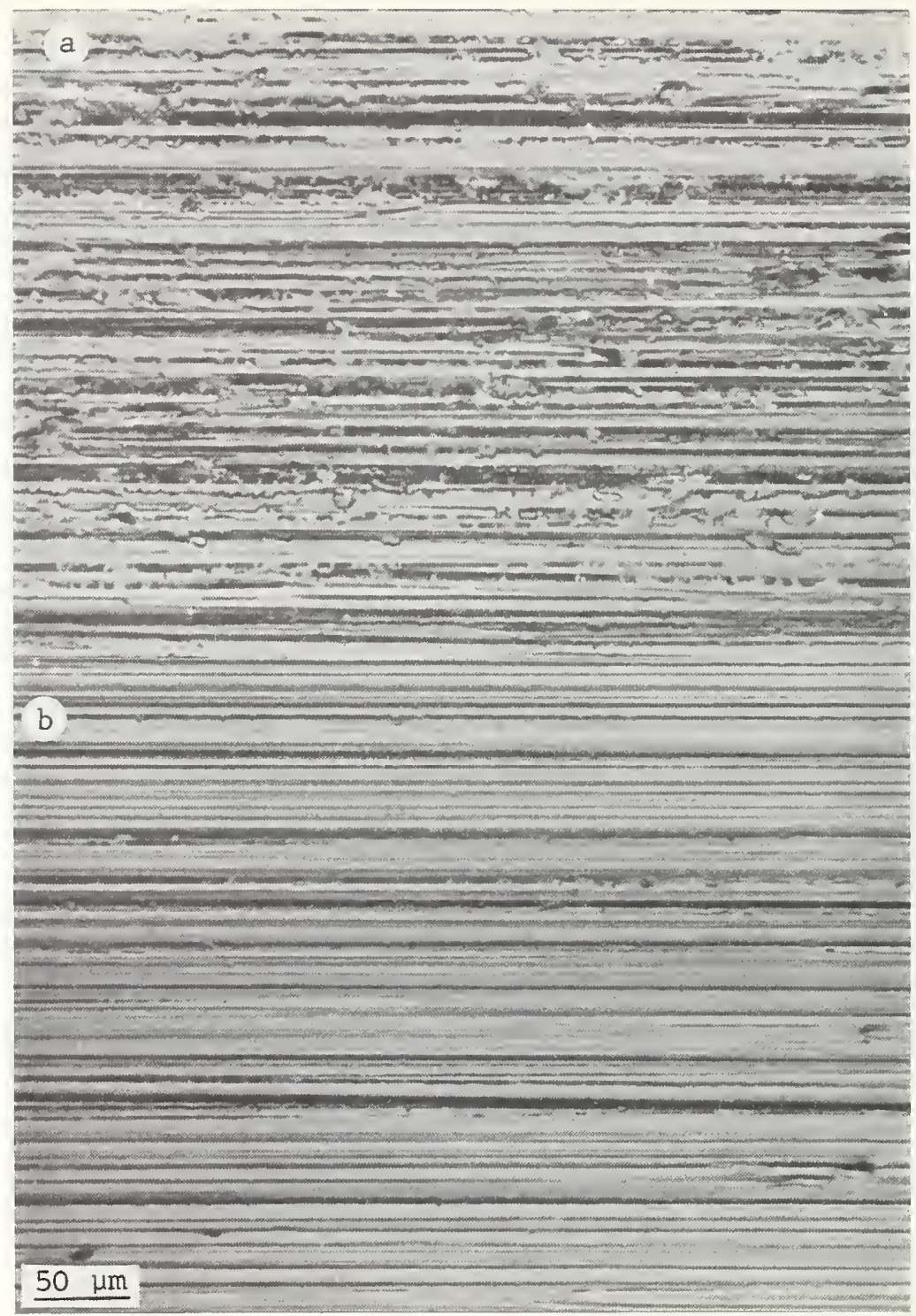

Figure 9. Development of the wear surface during abrasion on silicon carbide abrasive paper. (a) rough surface formed after $\sim 20 \mathrm{~cm}$ of sliding; (b) smoother surface formed after $\sim 1000 \mathrm{~cm}$ of sliding 


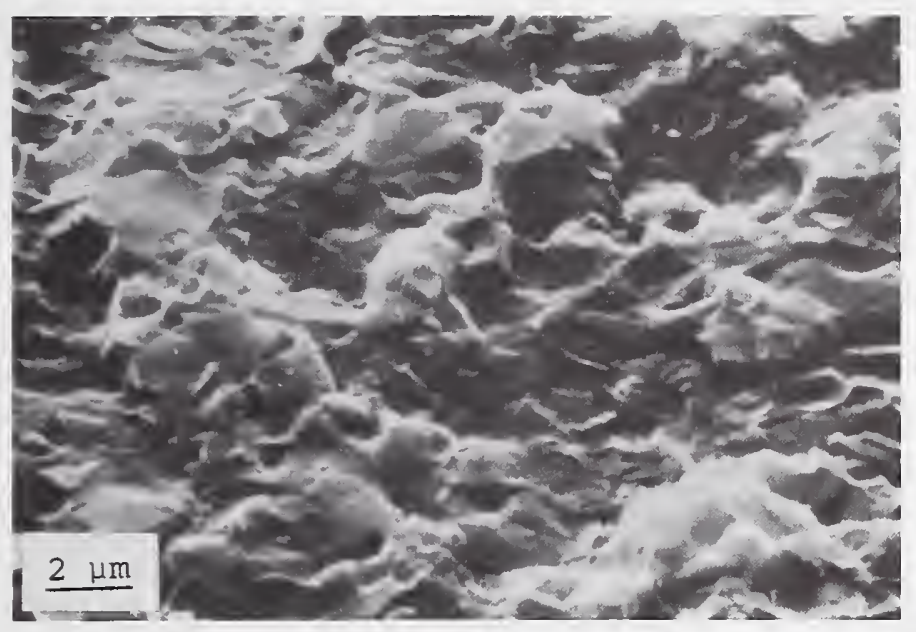

Figure 10. Scanning electron micrograph of silicon carbide plate 


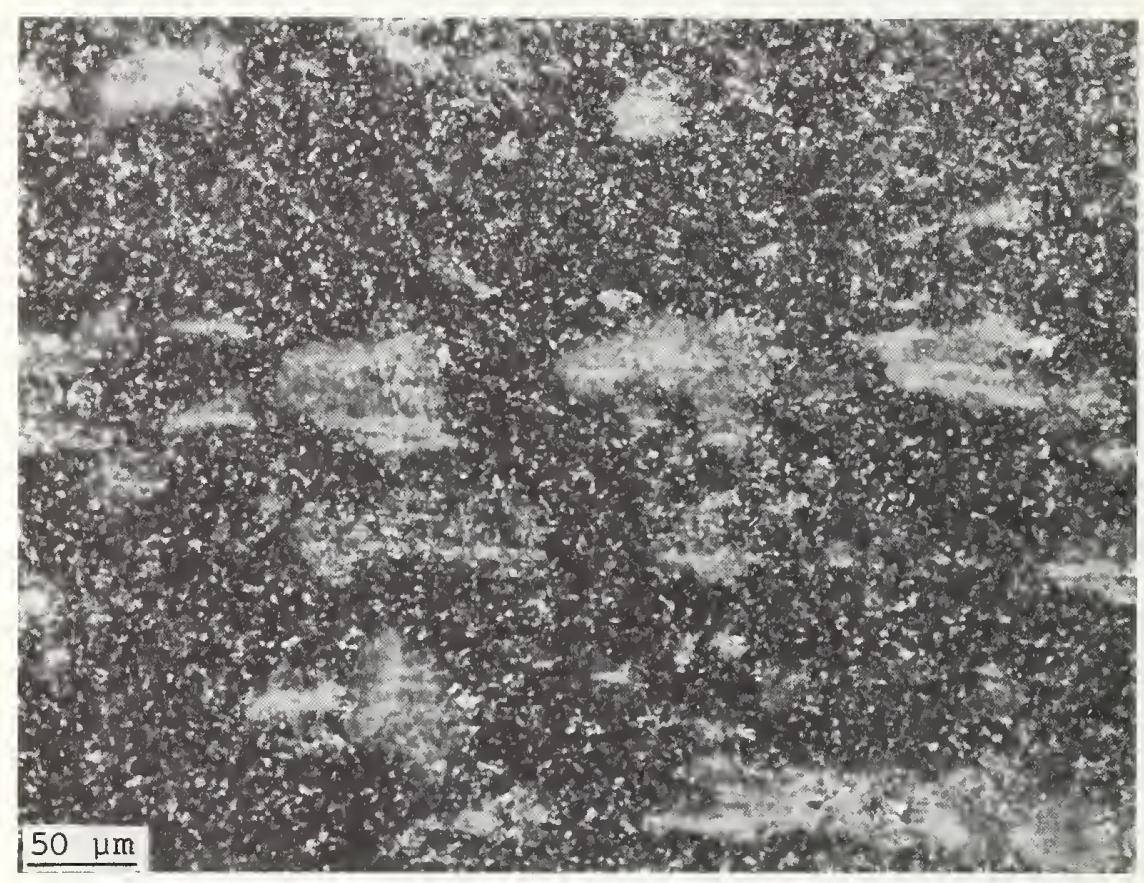

Figure 11. Wear debris formed at the cutting asperities on the silicon carbide plate (ethyl alcohol as lubricant) 


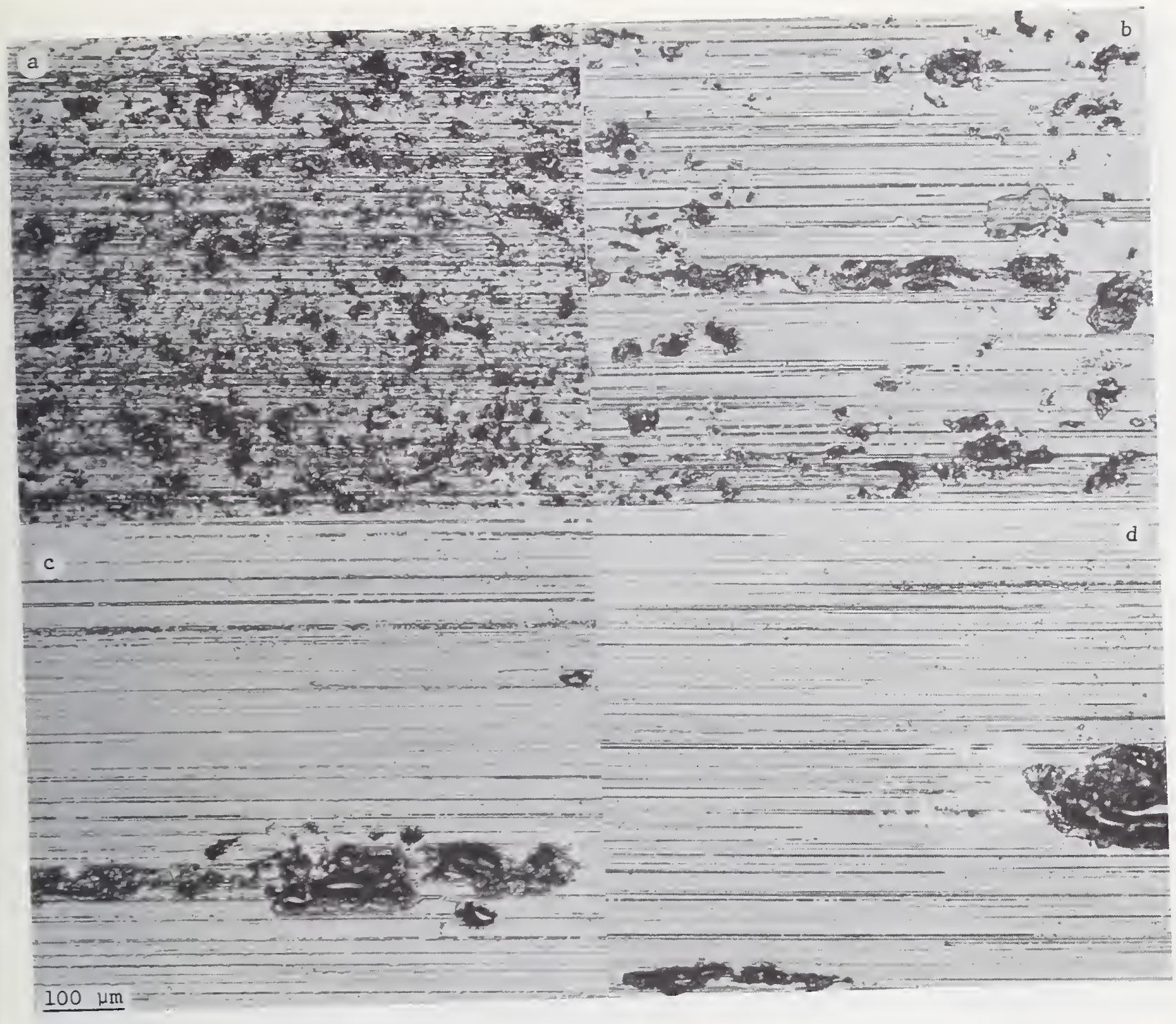

Figure 12. Wear surface of the glass spheres formed by abrasion against the sllicon carbide plate. Track changed every 10 seconds to approximate continuous wear. (a) water, (b) butyl alcohol, (c) heptyl alcohol, and (d) dodecyl alcohol. 


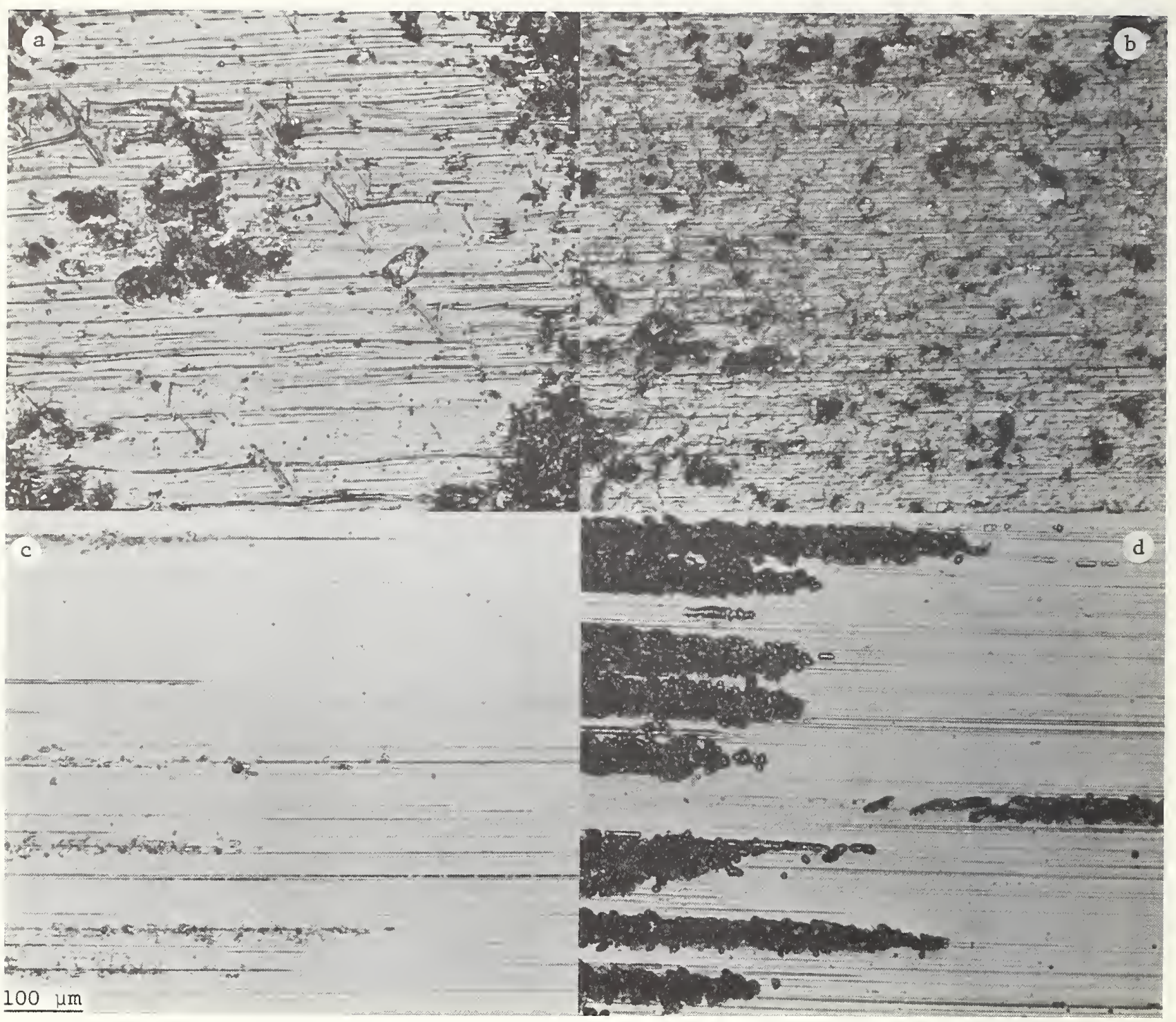

Figure 13. Wear surface formed by abrading the soda lime silicate spheres against the silicon carbide plate in water. (a) after $\sim 3 \mathrm{~cm}$ of sliding, (b) after $\sim 100 \mathrm{~cm}$ of sliding (3 seconds), (c) after $\sim 6000 \mathrm{~cm}$ of sliding (5 minutes), (d) same as (c), but etched with H.F. 


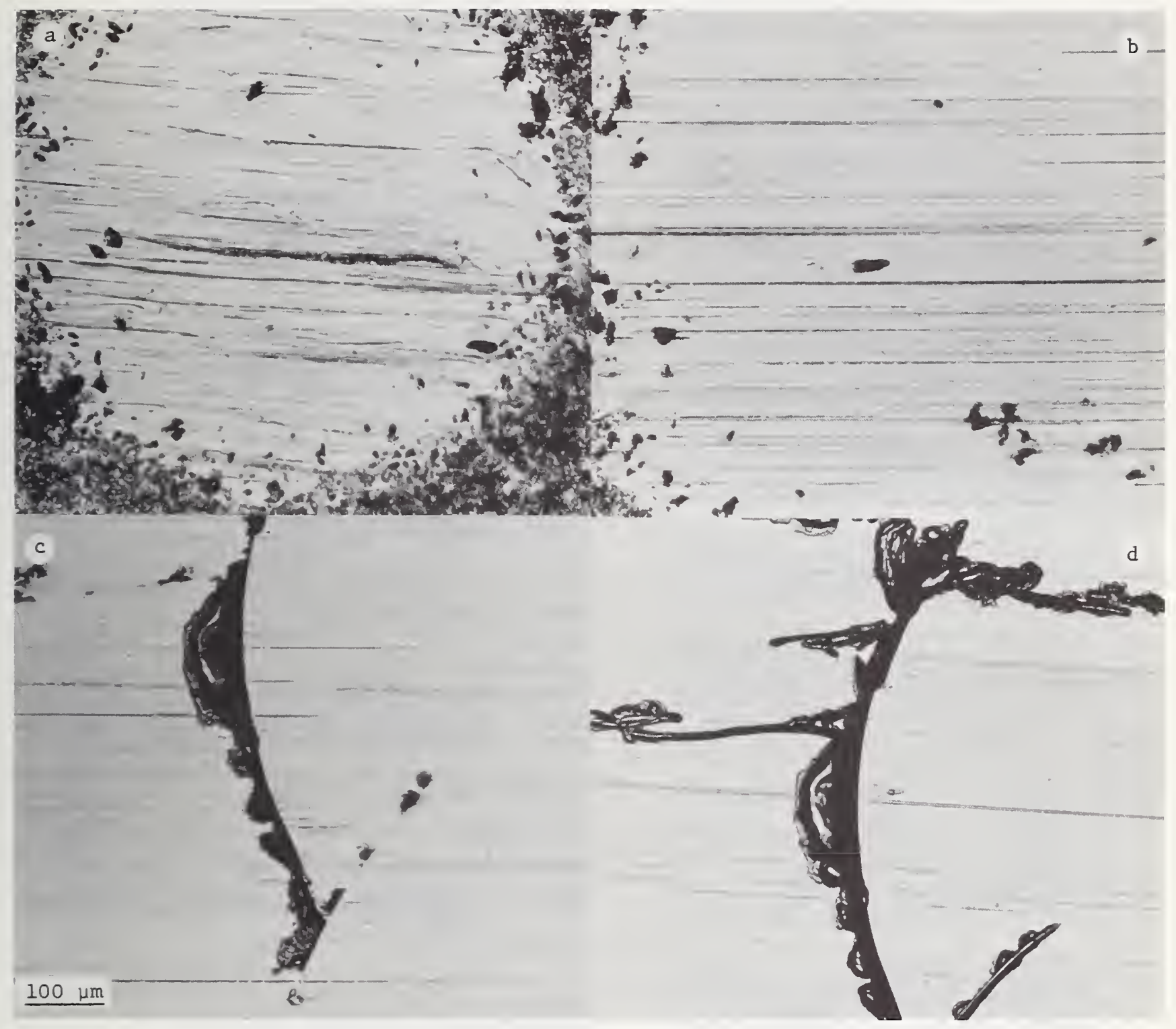

Figure 14. Wear surface formed by abrading the soda lime silicate glass spheres against the silicon carbide plate in decyl alcohol. (a) after $\sim 6 \mathrm{~cm}$ of sliding, (b) after $\sim 100 \mathrm{~cm}$ of sliding ( 3 seconds), (c) after $\sim 6000$ cm of sliding (5 minutes), (d) same as (c), but etched with H.F. The large curved crack in (c) and (d) was not formed by the abrasion process. Cracks of this sort were frequently observed in the as-received spheres. 
Organization

Office of Naval Research Department of the Navy

Attn: Code 471

Arlington, Virginia 22217

Director

Office of Naval Research

Branch Office

495 summer street

Boston, Massachusetts 02210

Commanding Officer

Office of Naval Research

New York Area Office

207 west 24th Street

New York, New York 10011

Director

Office of Naval Research

Branch Office

1030 East Green Street

Pasadena, California 91101

Commanding officer

Office of Naval Research

San Francisco Area Office

San Francisco, California 94102

Commanding officer

Naval Weapons Laboratory

Attn: Research Division

Dahlgren, Virginia 22448

\section{Organization}

Director

Naval Research Laboratory

Attn: Technical Information officer Code 2000

Washington, D. C. 20390

Director

Naval Research Laboratory

Attn: Technical Information officer Code 2020

Washington, D. C. 20390

Director

Naval Research Laboratory

Attn: Technical Information officer Code 6000

Washington, D. C. 20390

Director

Naval Research Laboratory

Attn: Technical Information officer Code 6100

Washington, D. C. 20390

Director

Naval Research Laboratory

Attn: Technical Information officer Code 6300

Washington, D. C. 20390

Director

Naval Research Laboratory

Attn: Technical Information officer Code 6400

Washington, D.C. 20390

Director

Naval Research Laboratory

Attn: Library

Code 2029 (ONRI)

Washington, D. C. 20390 
Commander

Naval Air Systems Command

Department of the Navy

Attn: Code AIR 320A

Washington, D. C. 20360

Commander

Naval Air system Command

Department of the Navy

Attn: Code AIR 5203

Washington, D. C. 20360

Commander

Naval Ordnance Systems Command

Department of the Navy

Attn: Code ORD 033

Washington, D. C. 20360

Commanding Officer

Naval Air Development Center

Aeronautical Materials Div.

Johnsville

Attn: Code MAM

Warminster, Pa. 18974

Commanding officer

Naval Ordnance Laboratory

Attn: Code 210

White Oak

Silver Spring, Maryland 20910

Commander

Naval Ship Systems Command

Department of the Navy

Attn: Code 0342

Washington, D. C. 20360

Commanding officer

Naval Civil Engineering Laboratory

Attn: Code L70

Port Hueneme, California 93041

Commander

Naval Ship Engineering Center

Department of the Navy

Attn: Code 6101

Washington, D. C. 20360
Naval Ships R\&D Laboratory

Annapolis Division

Attn: Code A800

Annapolis, Maryland 21402

Commanding Officer

Naval Ships R\&D Center

Attn: Code 747

Washington, D. C. 20007

U. S. Naval Postgraduate School

Attn: Department of Chemistry and Material Science

Monterey, California 93940

Commander Naval Weapons Center

Naval Weapons Center

Attn: Code 5560

China Lake, California 93555

Commander

Naval Underseas Warfare Center

Pasadena, California 92152

Scientific Advisor

Commandant of the Marine Corps

Attn: Code AX

Washington, D. C. 20380

Commanding officer

Army Research Office, Durham

Box CM, Duke Station

Attn: Metallurgy \& Ceramics Div. Durham, North Carolina 27706

Office of Scientific Research Department of the Air Force Attn: Solid State Div. (SRPS) Washington, D. C. 20333

Defense Documentation Center Cameron Station

Alexandria, Virginia 22314 
National Bureau of Standards

Attn: Metallurgy Division

Washington, D. C. 20234

National Bureau of Standards

Attn: Inorganic Materials Div.

Washington, D. C. 20234

Atomic Energy Commission

Attn: Metals \& Materials Branch

Washington, D. C. 20545

Argonne National Laboratory

Metallurgy Division

P. O. Box 299

Lemont, Illinois 60439

Brookhaven National Laboratory

Technical Information Division

Attn: Research Library

Upton, Long Island, New York 11973

\section{Library}

Bldg. 50, Room 134

Lawrence Radiation Laboratory

Berkeley, California 94720

Los Alamos Scientific Laboratory

P. O. Box 1663

Attn: Report Librarian

Los Alamos, New Mexico 87544

Commanding officer

Army Materials and Mechanics

Research Center

Attn: Res. Programs office (AMXMR-P)

Watertown, Massachusetts 02172

\section{Director}

Metals \& Ceramics Division

Oak Ridge National Laboratory

P. O. Box X

Oak Ridge, Tennessee 37830

Commanding officer

Naval Underwater Systems Center

Newport, Rhode Island 02844
Aerospace Research Laboratories

Wright-Patterson AFB

Building 450

Dayton, Ohio 45433

Defense Metals Information Center

Battelle Memorial Institute

$505 \mathrm{King}$ Avenue

Columbus, Ohio 43201

Army Electronics Command

Evans Signal Laboratory

Solid State Devices Branch

c/o Senior Navy Liaison officer

Fort Monmouth, New Jersey 07703

Commanding General

Department of the Army

Frankford Arsenal

Attn: ORDBA-1320, 64-4

Philadelphia, Pennsylvania 19137

Executive Director

Materials Advisory Board

National Academy of Sciences

2101 Constitution Avenue, N. W.

Washington, D. C. 20418

NASA Headquarters

Attn: Code RRM

Washington, D. C. 20546

Air Force Materials Lab

Wright-Patterson AFB

Attn: MAMC

Dayton, Ohio 45433

Air Force Materials I.ab

hright-Patterson AFB

Attn: MAAM

Dayton, Ohio 45433

Deep Submergence Systems Project

Attn: DSSP-00111

Washington, D. C. 20360 
Advanced Research Projects Agency Attn: Director, Materials Science Washington, D. C. 20301

Department of the Interior

Bureau of Mines

Attn: Science \& Engineering Advisor

Washington, D. C. 20240

Defense Ceramics Information Center Battelle Memorial Institute 505 King Avenue

Columbus, Ohio 43201

National Aeronautics \& Space Adm. Lewis Research Center

Attn: Iibrarian

21000 Brookpark Rd.

Cleveland, Ohio 44135

Naval Missile Center

Materials Consultant

Code 3312-1

Point Mugu, California 93041

Commanding officer

Naval Weapons Center Corona Labs.

Corona, California 91720

Commander

Naval Air Test Center

Weapons systems Test Div. (Code OlA)

Patuxent River, Maryland 20670

Director

Ordnance Research Laboratory

P. O. Box 30

State College, Pennsylvania 16801
Director

Applied Physics Laboratory

Johns Hopkins University

8621 Georgia Avenue

Silver Spring, Maryland 20901

Director

Applied Physics Laboratory

1013 Northeast Fortieth st.

Seattle, Washington 98105

Materials Sciences Group

Code 5130.1

271 Catalina Boulevard

Navy Electronics Laboratory

San Diego, California 92152

Dr. Waldo K. Lyon

Director, Arctic Submarine Laboratory

Code 90, Building 371

Naval Undersea R\&D Center

San Diego, California 92132

Dr. R. Nathan Katz

Ceramics Division

U.S. Army Materials \& Mechanics Research Center

Watertown, Mass. 02172 
Professor R, Roy

Materials Research Laboratory

Pennsylvania State University

University Park, Pennsylvania 16802

Professor D. H. Whitmore

Department of Metallurgy

Northwestern University

Evanston, Illinois 60201

Professor J. A. Pask

Department of Mineral Technology

University of California

Berkeley, California 94720

Professor D. Turnbull

Div. of Engineering and Applied Sci.

Harvard University

Pierce Hall

Cambridge, Massachusetts 02100

Dr. T. Vasilos

AVCO Corporation

Research and Advanced Development Div.

201 Lowell st.

Wilmington, Massachusetts 01887

Dr. H. A. Perry

Naval Ordnance Laboratory

Code 230

Silver Spring, Maryland 20910

Dr. Paul Smith

Crystals Branch, Code 6430

Naval Research Laboratory

Washington, D. C. 20390

Dr. A. R. C. Westwood

RIAS Division

Martin-Marietta Corporation

1450 South Rolling Road

Baltimore, Maryland 21227

Dr. W. Haller

Chief, Inorganic Glass Section

National Bureau of Standards

Washington, D. C. 20234
Dr. R. H, Doremus

General Electric Corporation Metallurgy and Ceramics Lab. Schenectady, New York 12301

Professor G. R. Miller

Department of Ceramic Engineering University of Utah

Salt Lake City, Utah 84112

Dr. Philip I. Farnsworth

Materials Department

Battelle Northwest

P. O. Box 999

Richland, Washington 99352

Mr. G. H. Haertling

Ceramic Division

Sandia Corporation

Albuquerque, New Mexico 87101

Mr. I . Berman

Army Materials and Mechanics

Research Center

Watertown, Massachusetts 02171

Dr. F. F. Lange

Westinghouse Electric Corporation

Research Laboratories

Pittsburgh, Pennsylvania 15235

Professor H. A. McKinstry

Pennsylvania State University

Materials Research Laboratory

University Park, Pa. 16802

Professor T. A. Litovitz

Physics Department

Catholic University of America

washington, D. C. 20017

Dr. R. J. Stokes

Honeywell Corporate Research Center 10701 Lyndale Avenue South

Bloomington, Minnesota 55420 
Dr. Harold Liebowitz

Dean of Engineering

George Washington Univeristy

Washington, D. C. 20006

Dr. H. Kirchner

Ceramic Finishing Company

P. O. Box 498

State College, Pennsylvania 16801

P rofessor A. H. Heuer

Case Western Reserve University

University Circle

Cleveland, Ohio 44106

Dr. D. E. Niesz

Battelle Memorial Institue

505 King Avenue

Columbus, Ohio 43201

Dr. F. A. Kroger

University of Southern California

University Park

Los Angeles, California 90007

Dr. Sheldon M. Wiederhorn

National Bureau of Standards

Inorganic Materials Division

washington, D. C. 20234

Dr. C. O. Hulse

United Aircraft Research Labs

United Aircraft Corporation

East Hartford, Connecticut 06108

Professor M. H. Manghnani

University of Hawaii

Hawaii Institute of Geophysics

2525 Correa Road

Honolulu, Hawaii 96822

Dr. Stephen Malkin

Department of Mechanical Engineering University of Texas

Austin, Texas 78712

Prof. H. E. Wilhelm

Department of Mechanical Engineering

Colorado State iniversity

Fort Collins, Colorado 80521
$S$ tanford University

Dept. of Materials Sciences

Stanford, California 94305

Dr. R. K. MacCrone

Department of Materials Engineering

Rensselaer Polytechnic Institute

Troy, New York 12181

Dr. D. C. Mattis

Belfer Graduate School of Science

Yeshiva University

New York, New York 10033

Professor R. B. Williamson

College of Engineering

University of California

Berkeley, California 94720

Professor R.. W. Gould

Department of Metallurgical

and Materials Engineering

College of Engineering

University of Florida

Gainesville, Florida 32601

Professor V. S. Stubican

Department of Materials Science

Ceramic Science Section

Pennsylvania State University

University Park, Pennsylvania 16802

Dr. R. C. Anderson

Gereral Eiectric Company

Miniature Lamp Dept,, ijela Park

Cleveland, Ohio 44112

Dr. Bert Zauderer

MHD Program, Advanced Studies

Room L-9513-VFSC

General Electric Company

P. C. Eox 8555

Philadelphia, Pennsylvania 19101

Prof. C. F. Fisher, Jr.

Department of Mechanical and Aerospace Engineering

University of Tennessee

Knoxville, Tennessee 37916 


\begin{tabular}{|c|c|c|c|}
\hline $\begin{array}{l}\text { U.S. DEPT. OF COMM. } \\
\text { BIBLIOGRAPHIC DATA } \\
\text { SHEET }\end{array}$ & $\begin{array}{l}\text { 1. PUIBLICATION OR RIPORT NO. } \\
\text { NBSIR 74-569 }\end{array}$ & $\begin{array}{l}\text { 2. Gov't Accession } \\
\text { No. }\end{array}$ & 3. Recipient's Accession No. \\
\hline \multirow{2}{*}{\multicolumn{3}{|c|}{$\begin{array}{l}\text { 4. TITII: ANI SUBTIII: } \\
\text { Influence of ITormal Alcohols on the Abrasive Wear of Glass }\end{array}$}} & $\begin{array}{l}\text { 5. P'ublication I)ate } \\
\text { July } 1974\end{array}$ \\
\hline & & & 6. Performing Organization Code \\
\hline \multicolumn{3}{|c|}{$\begin{array}{l}\text { 7. AUTHOR(S) } \\
\text { S. M. Wiederhorn and D. E. Roberts }\end{array}$} & $\begin{array}{l}\text { 8. Performing Organ. Repore No. } \\
\text { IBSIR 74-569 }\end{array}$ \\
\hline \multicolumn{2}{|c|}{ 9. PERIFORMING ORGANIZATION NAME AND ADDR ESS } & & $\begin{array}{l}\text { 10. Project/Task/Work Unit No. } \\
3130453\end{array}$ \\
\hline \multicolumn{3}{|c|}{$\begin{array}{l}\text { NATIONAL BUREAU OF STANDARDS } \\
\text { DEPARTMENT OF COMMERCE } \\
\text { WASHINGTON, D.C. } 20234\end{array}$} & $\begin{array}{l}\text { 11. Contract/Grant No. } \\
\text { NR } 032-535\end{array}$ \\
\hline \multirow{2}{*}{\multicolumn{3}{|c|}{$\begin{array}{l}\text { 12. Sponsoring Organization Name and Complete Address (Street, City, State, ZIP) } \\
\text { Office of iTaval Research } \\
\text { Code } 471 \\
800 \text { iv. Quincy St. } \\
\text { Arlington, Virginia } 22217\end{array}$}} & $\begin{array}{l}\text { 13. Type of Refort \& Perrod } \\
\text { Covered Interim } \\
7-1-73 \text { thru } 6-30-74\end{array}$ \\
\hline & & & 14. Sponsoring Agency Codc. \\
\hline
\end{tabular}

15. SUPPI.EMFN TARY NOTES

To be published in wear

16. AlBSTRACT (A 200-word or less factual summary of most significant information. If document includes a significant bibliography or literature survey, mention it here.)

Normal alcohols were used as lubricants in a study of friction and wear of soda lime silicate glass against silicon carbide. Abrasion surfaces were 600 grit silicon car-bide paper and a roughened plate of hot-pressed silicon carbide. Generally, as the abrasion time or the alcohol chain length increased, the coefficient of friction decreased. This result was attributed to better lubrication of the abrading surfaces by the long chain length alcohols. The wear rate and the coefficient of friction were strongly dependent on pullout of carbide grains from the silicon carbide paper. Wear on fresh abrasive paper was independent of alcohol chain length. As the paper becomes used, long chain length alcohols were more effective cutting fluids. On the silicon carbide plate, the wear rate decreased in a non-linear fashion as the alcohol chain length increased. For all conditions, the highest wear rate and coefficient of friction were obtained in water. Data are explained in terms of classical theories of friction and wear.

17. KEY WORDS (six to twelve entries; alphabetical order; capitalize only the first letter of the first key word unless a proper name; separated by semicolons)

Alcohol; glass; mechanism; silicon carbide; wear.

18. AVAILABILITY [Unlimited

X For Official Distribution. Do Not Release to NTIS

Order From Sup, of Doc., U.S. Government Printing Office Washington, D.C. 20402, SD Cat. No.C13

Order From National Technical Information Service (NTIS) Springfield, Virginia 22151

\begin{tabular}{|l|c|}
\hline $\begin{array}{l}\text { 19. SECURITY CI.ASS } \\
\text { (THIS REPORT) } \\
\text { UNCL ASSIFIED) }\end{array}$ & 21. NO. OF PAGES \\
\hline $\begin{array}{l}\text { 20. SECURITY CLASS } \\
\text { (THIS PAGE) }\end{array}$ & 22. Price \\
UNCLASSIFIED & USCOMM-DC 29042-P74 \\
\hline
\end{tabular}

